\title{
Efficacy of vafidemstat in experimental autoimmune encephalomyelitis highlights the KDM1A/RCOR1/HDAC epigenetic axis in multiple sclerosis
}

\section{Fernando Cavalcanti}

Oryzon Genomics, S.A.

\section{Elena Gonzalez-Rey}

Institute of Parasitology and Biomedicine Lopez-Neyra, IPBLN-CSIC https://orcid.org/0000-0003-39179020

\section{Mario Delgado}

Institute of Parasitology and Biomedicine Lopez-Neyra, IPBLN-CSIC

\section{Leyre Mestre}

Department of Functional and Systems Neurobiology, Cajal Institute (CSIC) https://orcid.org/00000001-6970-2316

\section{Carmen Guaza}

Department of Functional and Systems Neurobiology, Cajal Institute (CSIC) https://orcid.org/00000003-3240-9807

\section{Michele MP Lufino}

Oryzon Genomics, S.A. https://orcid.org/0000-0002-0854-9255

Jordi Xaus

Oryzon Genomics, S.A.

\section{Cristina Mascaró}

Oryzon Genomics, S.A. https://orcid.org/0000-0003-0478-9152

\section{Serena Lunardi}

Oryzon Genomics, S.A. https://orcid.org/0000-0001-6105-4430

\section{Natalia Sacilotto}

Oryzon Genomics, S.A. https://orcid.org/0000-0002-2027-4354

\section{Paola Dessanti}

Oryzon Genomics, S.A.

\section{David Rotllant}

Oryzon Genomics, S.A. https://orcid.org/0000-0002-1186-4918

\section{Xavier Navarro}

Departament de Biologia Cel.lular, Fisiologia i Immunologia, Institut de Neurociències, Universitat Autònoma de Barcelona, and Centro de Investigación Biomédica en Red sobre Enfermedades 
Neurodegenerativas (CIBERNED) https://orcid.org/0000-0001-9849-902X

\section{Mireia Herrando-Grabulosa}

Departament de Biologia Cel.lular, Fisiologia i Immunologia, Institut de Neurociències, Universitat Autònoma de Barcelona, and Centro de Investigación Biomédica en Red sobre Enfermedades

Neurodegenerativas (CIBERNED) https://orcid.org/0000-0002-6685-3220

\section{Carlos Buesa}

Oryzon Genomics, S.A. https://orcid.org/0000-0001-6293-2514

\section{Tamara Maes ( $\nabla$ tmaes@oryzon.com )}

Oryzon Genomics, S.A. https://orcid.org/0000-0001-5104-6867

\section{Research Article}

Keywords: Epigenetics, KDM1A, vafidemstat, multiple sclerosis

Posted Date: November 25th, 2020

DOl: https://doi.org/10.21203/rs.3.rs-114482/v1

License: (a) (1) This work is licensed under a Creative Commons Attribution 4.0 International License. Read Full License 
Title: Efficacy of vafidemstat in experimental autoimmune encephalomyelitis highlights the KDM1A/RCOR1/HDAC epigenetic axis in multiple sclerosis Authors: Fernando Cavalcanti ${ }^{1}$, Elena Gonzalez-Rey ${ }^{2}$, Mario Delgado ${ }^{2}$, Leyre Mestre $^{3}$, Carmen Guaza ${ }^{3}$, Michele MP Lufino', Jordi Xaus¹, Cristina Mascaró1, Serena Lunardi ${ }^{1}$, Natalia Sacilotto ${ }^{1}$, Paola Dessanti ${ }^{1}$, David Rotllant ${ }^{1}$, Xavier Navarro $^{4}$, Mireia Herrando-Grabulosa ${ }^{4}$, Carlos Buesa ${ }^{1}$ and Tamara Maes ${ }^{1}$

1 Oryzon Genomics, S.A. Carrer Sant Ferran 74, 08940 Cornellà de Llobregat, Spain.

2 Institute of Parasitology and Biomedicine Lopez-Neyra, IPBLN-CSIC, Granada, Spain.

${ }^{3}$ Department of Functional and Systems Neurobiology, Cajal Institute (CSIC), Madrid, Spain.

${ }^{4}$ Departament de Biologia Cel.Iular, Fisiologia i Immunologia, Institut de Neurociències, Universitat Autònoma de Barcelona, and Centro de Investigación Biomédica en Red sobre Enfermedades Neurodegenerativas (CIBERNED), Bellaterra, Spain.

Running title: vafidemstat epigenetic immune modulation Corresponding author

Tamara Maes

Address: Oryzon Genomics, S.A. Carrer Sant Ferran 74, 08940 Cornellà de Llobregat, Spain

Telephone number: +34665602247 Fax number: +34 933774028

Email: tmaes@oryzon.com 


\section{Abstract \\ Background}

Vafidemstat (ORY-2001) is a clinical stage inhibitor of the Lysine Specific Demethylase KDM1A in development for treatment of neurodegenerative and psychiatric diseases. KDM1A demethylates H3K4me1/2 and together with the histone deacetylases HDAC1/2, it forms part of co-repressor complexes recruited by zinc finger factors to control transcription. The exact role of KDM1A in neuroinflammation remained to be explored.

\section{Methods}

Compounds were administered p.o. gavage to mice with MOG35-55 induced experimental autoimmune encephalomyelitis or mice infected with Theiler's murine encephalomyelitis virus. Immune cell infiltration was analyzed by immunohistochemistry. Cytokine and chemokine levels were analyzed by ELISA. Genome wide gene expression in spinal cord and brain were analyzed by two-color microarray analysis and qRT-PCR.

\section{Results}

ORY-2001 improved the clinical score in mouse experimental autoimmune encephalomyelitis and in mice infected with the Theiler's murine encephalomyelitis virus. The compound reduced lymphocyte egress and infiltration of immune cells in the spinal cord and prevented demyelination. ORY-2001 was more effective and/or faster acting than a sphingosine 1-phosphate receptor antagonist in the effector phase of the disease and reduced the induction of the inflammatory gene expression signature in the central nervous system more potently. Gene expression changes and axonal protection in animals, and protection against glutamate excitoxicity in spinal cord explants support that ORY-2001 has neuroprotective qualities.

\section{Conclusions}

ORY-2001 exerts therapeutic activity in two mouse models of multiple sclerosis. The anti-inflammatory properties of ORY-2001 are being tested in a Phase Ila clinical trial in patients with relapse remitting and secondary progressive multiple sclerosis, and in severely ill COVID-19 patients at risk for acute respiratory distress syndrome. 


\section{Graphical Abstract}

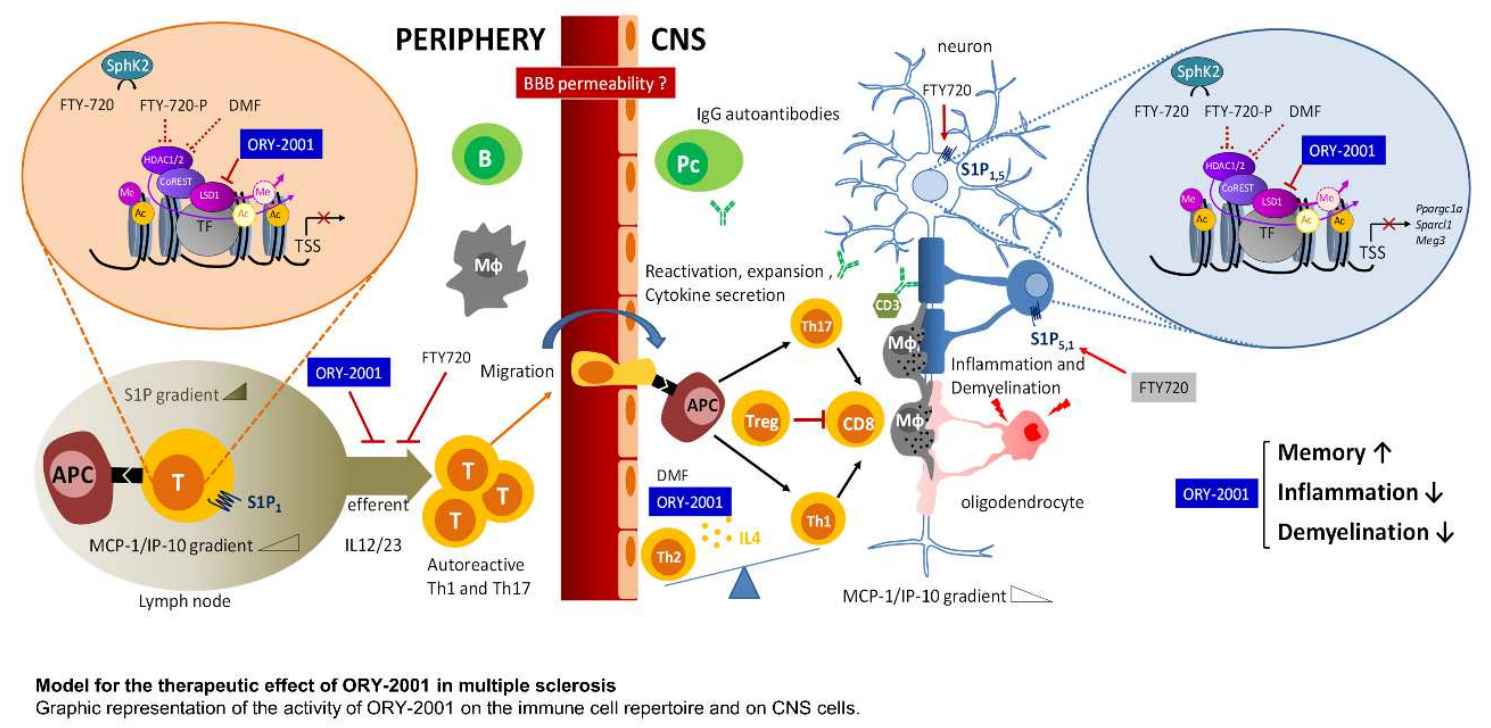

Keywords: Epigenetics, KDM1A, vafidemstat, multiple sclerosis

\section{Background}

Multiple sclerosis (MS) is a neurodegenerative disease characterized by an autoimmune response against myelin sheaths made by oligodendrocytes that surround central axons, thus resulting in demyelination and failure of impulse conduction, progressive axonal loss, and profound dysfunctions of the central nervous system (CNS). In addition to physical disability, it has become clear that cognition and behavioral problems such as aggression and others are also common in MS patients [1, 2, 3]. The etiology of the disease is unknown, but an epigenetic component appears to influence the onset and progression of the disease $[4,5]$.

Vafidemstat (ORY-2001) was identified as an inhibitor of the histone H3K4me1/2 demethylase 1 (KDM1A, LSD1) and Monoamine Oxidase B (MAO-B). KDM1A is located in the nucleus and demethylates histone H3K4me1/2. Together with the histone deacetylases HDAC1/2, KDM1A forms part of co-repressor complexes recruited by zinc finger factors to exert epigenetic control of transcription [6, 7]. MAO-B metabolizes primary amines like dopamine and plays an important role in the control of 
neurotransmitters level [8]. ORY-2001 is an orally bioavailable, brain penetrant compound that rescues cognition and behavioral alterations such as aggression in SAMP8 mice, a model for Alzheimer's disease (AD); and reverts social withdrawal in a rat rearing isolation model. Inhibition of KDM1A was key for in vivo efficacy. ORY-2001 upregulates genes important for synaptic plasticity and cognition and reduces the inflammation signature in the hippocampus of SAMP8 mice, including S100A9 and Tcell receptor b genes [9]. Upregulation of S100A9 has been described both in MS [10] and in Experimental Autoimmune Encephalomyelitis (EAE) mice. Furthermore, compounds that disrupt binding of S100A9 to the Toll-Like Receptor 4 (TLR4) were shown to inhibit acute EAE in mice [11], illustrating the relevance of this biomarker to MS. Therefore, we decided to test ORY-2001 in preclinical models for multiple sclerosis.

\section{Methods}

\section{Reagents and Resources}

Details of all reagents and resources used in this manuscript are included in Table A1 in Additional File 1.

\section{Experimental immune encephalomyelitis (EAE)}

Animal housing and care: Female C57BL/6 mice (8 weeks old, 25-30gr) obtained from Harlan Interfauna Iberica were housed in cages in specific pathogen free conditions with a temperature range between $18-22^{\circ} \mathrm{C}$ and $30-70 \%$ relative humidity range. The light/dark cycle was maintained at 12:12 hours (lighting switch on at 7:00 a.m.). All the animals were maintained with 2914 Irradiated Teklad Global 14\% Protein Rodent Maintenance Diet (Harlan) provided ad libitum. Autoclaved tap water was provided ad libitum. Mice remained in quarantine for one week prior to the initiation of the experiments.

Induction of chronic EAE: To induce chronic EAE, C57BL/6 mice were immunized s.c. with $100 \mu \mathrm{g}$ of the myelin oligodendrocyte glycoprotein fragment MOG35-55 emulsified 
in complete Freund adjuvant containing $4 \mathrm{mg} / \mathrm{ml}$ Mycobacterium tuberculosis H37 RA. Mice also received i.p. injections of $200 \mathrm{ng}$ of pertussis toxin on days 0 and 2 [12].

Randomization and blinding: After induction of chronic EAE and before initiation of treatment, animals were randomly distributed across experimental groups. The research group was blind to the identity of the compounds received for treatment. Mice were scored for daily signs of EAE by two technicians that were blind to treatment. Histopathological analysis was performed by two independent investigators that were blind to treatment.

Treatment of EAE mice: Animals were treated with ORY-2001 $\left(\mathrm{IC}_{50} \mathrm{KDM} 1 \mathrm{~A}=101 \pm 40\right.$ $n M ; I C_{50} M A O-B=73 \pm 34$ nM), ORY-LSD1 $\left(I_{50} K D M 1 A=10 \pm 3 n M ; I C_{50} M A O-B>\right.$ $100 \mu \mathrm{M})$, rasagiline (Waterstone, Cat\# WS104114) (IC $\mathrm{F}_{50} \mathrm{KDM} 1 \mathrm{~A}>100 \mu \mathrm{M}$; IC $\mathrm{C}_{50} \mathrm{MAO}-\mathrm{B}$ $=69 \pm 0.5 \mathrm{nM}$ ) or FTY720 (Cayman Chemical, Cat\# 10006292).

Initial assessment: Treatment consisted in the administration of ORY-2001 (at 3 and 1 $\mathrm{mg} / \mathrm{kg}$ ) by oral gavage starting after the onset of the disease (day 12 post-immunization), once a day, for five consecutive days from day 12 to day 16 postimmunization and from day 19 to day 23 postimmunization. Control mice were orally treated with vehicle [2\% v/v Tween-80 $+98 \%$ HPßCD $(13 \% \mathrm{w} / \mathrm{v})]$ following the same regime of administration than ORY-2001 treatment.

Dose finding and comparison: Treatment consisted in the administration of ORY-2001 (3; $1 ; 0.5$ and $0.05 \mathrm{mg} / \mathrm{kg})$, ORY-LSD1 $(0.18,0.09$ and $0.06 \mathrm{mg} / \mathrm{kg})$ or rasagiline $(3$ $\mathrm{mg} / \mathrm{kg}$ ) by oral gavage starting after the onset of the disease (day 12 post-immunization). The dose range used for each compound was function of the potency of LSD1 inhibition of each compound. Compounds were administered once daily in two cycles, from day 12 to 16 and from day 19 to 23 post-immunization. Control mice were treated with vehicle $[2 \% \mathrm{v} / \mathrm{v}$ Tween $-80+98 \% \mathrm{HP} \beta \mathrm{CD}(13 \% \mathrm{w} / \mathrm{v})]$ following the same administration regime. Animals were scored for EAE symptoms until day 51 post-immunization. 
Mechanisms of action in EAE (sub-chronic phase): Treatment consisted in the administration of ORY-2001 $(0.5 \mathrm{mg} / \mathrm{kg})$ and ORY-LSD1 $(0.18 \mathrm{mg} / \mathrm{kg})$ by oral gavage starting after the onset of the disease, once a day, five consecutive days from day 12 to 16 and from day 19 to 23 post-immunization. Control mice were treated orally with vehicle $[2 \% \mathrm{v} / \mathrm{v}$ Tween- $80+98 \% \operatorname{HP} \beta C D(13 \% \mathrm{w} / \mathrm{v})]$ following the same administration regime. Samples were collected on day 26 post-immunization, 3 days after last dose. Mechanisms of action in EAE (effector phase): ORY-2001 $(0.5 \mathrm{mg} / \mathrm{kg})$ or FTY720 (1 $\mathrm{mg} / \mathrm{kg}$ ) were administered for five consecutive days after onset of the disease from day 12 to day 16 post-immunization, the expected time required for the control group to reach the maximal clinical score as determined in previous experiments. Control mice were orally treated with vehicle $[2 \% \mathrm{v} / \mathrm{v}$ Tween-80 $+98 \%$ HPBCD $(13 \% \mathrm{w} / \mathrm{v})]$ following the same administration regime. Samples were collected on day 17 post-immunization.

Symptomatology: Mice were scored daily for signs of EAE according to the following clinical scoring system: 0 , no clinical signs; 0.5 , partial loss of tail tonicity; 1 , complete loss of tail tonicity; 2, flaccid tail and abnormal gait; 3 , hind leg paralysis; 4 , hind leg paralysis with hind body paresis; 5 , hind and fore leg paralysis; and 6 , death.

EAE mice tissue collection and cell isolation: At day 17 or 26 post-immunization, mice were euthanized by intracardiac perfusion after pentobarbital anesthesia (Doletal). Blood samples, spleen, draining lymph nodes (DLNs: cervical, inguinal and axillary), brain, and spinal cord were removed. Serum samples were used for auto-antibody determination. Single-cell suspensions were obtained from spleen or pooled DLNs and used for determination of auto-reactive and inflammatory responses. Brain and spinal segments of the cervical and lumbar regions were prepared separately and processed for RNA isolation, protein extraction, and histopathological analysis.

\section{Sprague-Dawley pups for spinal cord organotypic cultures}

Animal care: Pups were obtained from the UAB Servei d'Estabulari breeding colony. Sprague-Dawley dams and pups were kept under standard conditions of light (12h/12h 
cycle, light $\mathrm{ON}$ at 8:00 am) and temperature $\left(21 \pm 2{ }^{\circ} \mathrm{C}\right)$ and dams were given food and water ad libitum.

Procedure: Spinal cords were obtained from lumbar spinal cords of 8-day-old SpragueDawley rat pups (P8). Pups were euthanized by pentobarbital overdose and the lumbar spinal cords collected under sterile conditions and placed in ice-cold high glucose containing (6.4 mg/ml) Gey's Balanced Salt Solution (GBSS). Meninges and roots were removed, and the spinal cord was transversely sectioned into $350 \mu \mathrm{m}$ slices with a Mcllwain Tissue Chopper.

Theiler's murine encephalomyelitis virus induced encephalomyelitis (TMEV). TMEV-IDD susceptible SJL/J female mice of 30 days old supplied by Charles Rivers were randomly assigned to standard cages (6 mice per cage) and maintained at our inhouse colony (Cajal Institute, Madrid, Spain) under standard conditions with water and food ad libitum and controlled conditions of temperature $\left(22 \pm 2^{\circ} \mathrm{C}\right)$ and humidity $(49 \pm$ $2 \%)$ with a daily cycle of 12 hours of light/12 hours of darkness.

Infection of mice with TMEV: Following 12 days from mice arrival, 6 weeks old mice were infected in the cerebral parenchyma with $2 \times 10^{6}$ plaque forming units $(\mathrm{pfu})$ of the Daniel's strain of TMEV in $30 \mu \mathrm{l}$ of DMEM supplemented with $5 \%$ fetal bovine serum. For the infection, mice were anesthetized with isoflurane (IsoFlo). The injection takes place in the right hemisphere of the brain cortex using a Hamilton syringe coupled to a pipette tip in such a way that it allows an exposure of the needle of about 2-3 $\mathrm{mm}$ and thus the virus is injected always at the same depth. Sham animals are subjected to the same protocol, but they only received $30 \mu$ of DMEM supplemented with $5 \%$ fetal bovine serum [13]. Treatment of TMEV infected mice: Treatment consisted in the administration of ORY2001 by oral gavage at the dose of $0.3 \mathrm{mg} / \mathrm{kg}$ and $1.0 \mathrm{mg} / \mathrm{kg}$, p.o. starting at the onset of the disease (day 72 post-infection), once a day for five consecutive days from day 72 to day 76 and from day 79 to day 83 post-infection. Control mice were treated with vehicle $[2 \% \mathrm{v} / \mathrm{v}$ Tween-80 $+98 \%$ HPßCD $(13 \% \mathrm{w} / \mathrm{v})]$ following the same administration regime 
(Figure 9A). Mice symptomatology and motor behavior was analyzed by trained observers blind to treatment and experimental group.

Weight of mice: The animals were weighed every week from the onset of infection.

Symptomatology: Animals were scored using the evaluation criterion developed by Moses Rodriguez (Mayo Clinic), source of the Daniel's strain of TMEV to assess General Appearance: Score 1 = Shaggy and scruffy hair; 2 = scruffy appearance and hunched back; 3 = no spontaneous movement, reduced induced activity; and Gait: Score 1 = mild ataxia with inconsistent waddling gait; 2 = moderate ataxia with consistent waddling gait; $3=$ severe ataxia with reduced righting response; $4=$ spastic paresis of hind legs.

Motor Function. The animal's motor function was assessed in the Activity Cage (Activity Monitor System Omnitech Electronics, Inc., Columbus, OH, EEUU); which consists of a four-compartment metacrylate cage, surrounded by sensors in such a way that it registers the movements of the mouse in both vertical and horizontal position and ambulation. The test consists in introducing the mice into two compartments of the cage placed diagonally so as not to interfere with the sensors of the other mouse. During two five-minute cycles (0-5 min, 5-10 min), horizontal activity (HACTV) or vertical activity (VACTV) are recorded. The first cycle evaluates the spontaneous activity to a new environment, the second measures the activity of the animal once habituated to the new environment. This task was performed on days $60,70,78$ and 86 post-infection.

Rotarod: The rotarod (Ugo Basile, Milan, Italia) consists of a rotating cylinder (roll) suspended above a cage floor turning at constant speed or acceleration. The system is completed with a stopwatch for each compartment that stops when the mouse falls from the roll to a lever on the bottom of the device. One week prior to the test, mice were trained and familiarized with test for one minute at constant speed. The length of time that mice stay on the rotating roll is a measure of their balance and motor coordination. The test consists in measuring the time that mice remain on the roll with constant acceleration for a maximum time of five minutes. Mice that developed strategies to stay 
on the roll (p.e. seeking support on the wall) were excluded from evaluation. The rotarod test was performed on day 72,78 and 86 post-infection.

Tissue collection: Mice were anesthetized on day 86 after infection by intraperitoneal pentobarbital administration (Dolethal; $50 \mathrm{mg} / \mathrm{kg}$ body weight) and perfused transcardially with saline $\left(0.9 \% \mathrm{NaCl}\right.$ in $\mathrm{H}_{2} \mathrm{O}$ MilliQ). Spinal cord was obtained by extrusion with saline, fixed overnight in $4 \%$ paraformaldehyde in $0.1 \mathrm{M} \mathrm{PB}$, cryoprotected with a $15 \%$ and later $30 \%$ solution of sucrose in PBS and frozen at $-80^{\circ} \mathrm{C}$ until used.

\section{Cell lines}

Human neuroblastoma SH-SY5Y cells (Cat\# CRL-2266) were seeded in 6-well plates in DMEM/F12 1:1 (Sigma), supplemented with 2mM glutamine and 10\% FBS (Sigma) and incubated at $37^{\circ} \mathrm{C}$ and $5 \% \mathrm{CO}_{2}$ in a humid atmosphere.

\section{Methods details}

Additional methods details can be found in Additional File 2.

\section{STATISTICS}

\section{EAE scoring}

All data are expressed as the mean \pm SEM. Two-way ANOVA (with appropriate post tests) was used to identity statistical differences between EAE scores over each day of the experiment for the vehicle and compound treated EAE mice. The rest of the experiments were statistically analyzed by t-test and by the non-parametric MannWhitney test and we evaluated if the normalizing transformations were effective by comparing results between parametric and non-parametric analysis. We used MannWhitney test when we found different results. We considered significance at $p<0.05$. All statistical analyses were performed using the Graph-Pad Prism software.

\section{TMEV scoring}

Statistical analysis. Dixon's exclusion criteria were applied to raw data. The data suited a normal distribution; a one-way ANOVA test was performed followed by Tukey's multiple comparisons test.

\section{Analysis of the EAE autoreactive response and flow cytometry studies}


All data are expressed as the mean \pm SEM. The EAE autoreactive response were statistically analyzed by one-way ANOVA followed by Tukey's multiple comparison test or non-parametric Mann-Whitney test. We considered significance at $p<0.05$. All statistical analyses were performed using the Graph-Pad Prism software.

\section{Microarray data analysis}

Data were normalized by modified nonlinear Q-splines normalization method and $\log _{2}$ (Sample/Vehicle) values calculated without background correction (which permits robust selection of differentially expressed genes yet may lead to sub-estimation of the magnitude of change for genes expressed near the detection limit). Differential expression was assessed with Polyphemus using robust statistics on the average technical replicates (3 replicates/gene oligo datapoint) after removing eventual outlier points (caused by dust or array imperfections). Polyphemous automatically defines the criteria for outlier elimination by assessing the intra-array technical variability using the signal distribution of controls probes (a large number of replicates present on the array). The $p$ values were calculated after outlier elimination based on the absolute value of the regularized t-statistics, which uses a Bayesian framework to derive the algorithm, using internal replicated controls to assess the minimum technical variability of the process.

Correlation between gene expression changes induced by different treatments was analysed calculating the Pearson correlation coefficient $r$ using the $\log _{2}($ Treatment/Veh) values for all genes expressed above background level $(n)$. The t values for the student's $t$ test were calculated as: $r \times(d f)^{1 / 2} \times\left(1-r^{2}\right)^{-1 / 2}$; with the degrees of freedom $d f=n-2$. The $p$ values were calculated as $2 \times \operatorname{tcd}(t, d f)$ using the $t$ distribution function with the Keisan Online Calculator service (https://keisan.casio.com/calculator). The analysis is highly sensitive and efficiently detects small systematic biases in the data measurement system, p.e. a difference in labeling efficiency in the Cy3 and Cy5 channel. Nevertheless, the $p$ values for the correlations between the $\log _{2}($ Treatment/Veh) values for each treatment were much lower than the $p$ values for the correlations between the $\log _{2}\left(\right.$ Treatment/Veh) and $\log _{2}($ Veh/Veh) values (Table A2 in Additional File 1). 


\section{qRT-PCR data analysis}

Mean $\mathrm{Cp}$ values for each datapoint were calculated after outlier elimination using Grubbs test (applied if the standard deviation of three technical PCR replicates was higher than Cp 0.25). $-\Delta \Delta \mathrm{Cp}$ (or analogous $-\Delta \Delta \mathrm{Ct}$ ) values relative to Vehicle were calculated as follows:

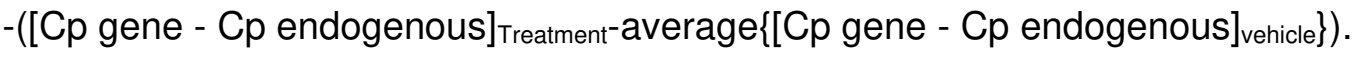

Vehicle and ORY-2001 were compared by unpaired t-test. t-test with Welch's correction was applied when the two distributions showed unequal variances.

\section{Biochemical assay data analysis}

Data were analyzed using the computer software GraphPad Prism (GraphPad Software, San Diego, CA). The fluorescence signal relative to the background (assay mixture in the absence of the enzyme) was subtracted from each fluorescent intensity data. Activity in the presence of compound was expressed as a percentage of fluorescence intensity in the absence of the compound. Statistical significance was determined using one-way ANOVA followed by Dunnett's multiple comparison.

\section{Spinal cord explant data analysis}

Motoneuron preservation data are presented as mean \pm SEM. Statistical significance was determined by one-way ANOVA followed by Dunnett's post hoc test, with $p<0.05$ considered statistically significant using the PC software GraphPad Prism (GraphPad Software, San Diego, CA).

\section{STUDY APPROVALS}

Studies using the EAE model were performed in accordance with the institutional guidelines for the care and use of laboratory animals (European Communities Council Directive 2010/63/EU) and approved sequentially by the Ethical Committee for Animal Experimentation at the IPBLN (protocol number CEEA-IPBLN-2016/12), by the Ethical Committee for Animal Experimentation at the CSIC (superior authorized body, protocol number 637/2017), and validated by the Ethical Committee for Animal Experimentation of the Junta de Andalucia with protocol number 13/04/2018/049. 
The experimental procedure for spinal cord organotypic cultures and chronic excitotoxicity treatment using Sprague-Dawley pups was performed in accordance with the European Communities Council Directive 2010/63/EU and approved by the Ethics Committee of Universitat Autònoma de Barcelona, under procedure CEEAH1963M.

Studies using the TMEV model were performed in accordance with EU (Directive 2010/63/EU) and National (Royal Decree 53/2013 BOE No. 34 and Comunidad de Madrid (ES 280790000184) guidelines, and the Ethics Committee on animal experimentation at the CSIC approved all the procedures described in this study under protocol number: 2013/03 CEEA-IC.

\section{Results}

\section{ORY-2001 in murine experimental autoimmune encephalomyelitis:}

Dose range, therapeutic window, and contribution of KDM1A and MAO-B inhibition In a first set of experiments, mice were immunized with $\mathrm{MOG}_{35-55}$ following a standard protocol. Following onset of symptoms on day 12, animals were treated during two weeks with ORY-2001 at 1 and $3 \mathrm{mg} / \mathrm{kg}$ (Figure A1, A in Additional File 3) or at 0.05, 0.5 and 1 $\mathrm{mg} / \mathrm{kg}$ (Figure 1, A) administered by oral gavage. The clinical score was monitored over time and animals were sacrificed on day 52 after immunization. ORY-2001 greatly inhibited the development of EAE symptoms, reflected in the cumulative disease score (Figure A1, B and C in Additional File 3) and reduced both the disease incidence and severity. The reduction of the clinical score became clear after a couple of days of treatment and was sustained for prolonged time after treatment interruption in all groups with exception of the dose at $0.05 \mathrm{mg} / \mathrm{kg}$, which relapsed around day 44 . ORY-2001 treatment was effective at doses that did not significantly impact the total number of circulating lymphocytes (Table A3 in Additional File 1). This therapeutic window (once the difference in exposure by oral gavage versus drinking water is accounted for) is similar to that observed for the beneficial effects of ORY-2001 on cognition in SAMP8 mice [9]. To dissect the relative contribution of the KDM1A vs MAO-B inhibitory 
component, we then compared the therapeutic efficacy of ORY-2001 with that of the selective KDM1A inhibitor ORY-LSD1 (0.06 or $0.18 \mathrm{mg} / \mathrm{kg}$ in Figure A1 D in Additional File 3 and 0.09 and $0.18 \mathrm{mg} / \mathrm{kg}$ in Figure $1 \mathrm{~B}$ ) and with the selective MAO-B inhibitor rasagiline ( $3 \mathrm{mg} / \mathrm{kg})$. ORY-LSD1 provided a significant improvement at some timepoints but the cumulative disease index did not reach significance (Figure $A 1, E$ and $F$ in Additional File 3), and the selective MAO-B inhibitor rasagiline was not effective although it appeared to induce a small delay of the onset of symptoms (Figure $1 \mathrm{C}$ and Figure $\mathrm{A} 1$ $\mathrm{G}$ in Additional File 3). At the end of the study $70-80$ and $60 \%$ of the mice treated with ORY-2001 and ORY-LSD1 did not show any or showed only mild clinical signs, versus 33 and $19 \%$ of the mice treated with rasagiline and vehicle. These results show that inhibition of KDM1A is key to the therapeutic effects of ORY-2001 in the EAE model, as was the case for its effect on cognition in SAMP8 mice [9].

\section{ORY-2001 has an immune modulatory effect}

A new EAE experiment was performed using $0.5 \mathrm{mg} / \mathrm{kg}$ ORY-2001 and $0.18 \mathrm{mg} / \mathrm{kg}$ ORYLSD1 in which animals were sacrificed in the sub-chronic phase to study the mechanism of action. Again, the compounds reduced the clinical score and ORY-2001 performed better than ORY-LSD1 (Figure 1D and Figure A1, $\mathrm{H}$ and I in Additional File 3).

EAE and MS are characterized by the activation of infiltrating and resident glial cells in the CNS, leading to de-regulation of inflammatory and autoreactive mediators. Autoreactive IFN-gamma-producing Th1 and IL-17-secreting Th17 cells infiltrate the CNS and promote disease progression [14]. To investigate if ORY-2001 could ameliorate EAE by reducing encephalitogenic T-cell responses and/or their migration to CNS, we analyzed the inflammatory and autoimmune response in the peripheral immune organs (spleen and lymph nodes) and CNS (brain and spinal cord). ORY-2001 greatly reduced the infiltration of inflammatory cells and demyelination in the spinal cord of EAE mice (Figure 1, E and F and Figure A1, J to R in Additional File 3). In the sub-chronic phase, neither ORY-2001 nor ORY-LSD1 produced changes in the ratio IgG2a/lgG1 (Figure 
1G) but ORY-2001 reduced lymphocyte egress from spleen and lymph nodes (Figure $1 \mathrm{H})$.

Myelin oligodendrocyte glycoprotein (MOG)-induced but not $a-C D 3$-induced $T$ cell proliferation was significantly decreased in cultured cell populations from spleens of ORY-2001 treated animals (Figure 2, A and B). Cytokine IL-4 was significantly increased in splenocytes induced by Concavalin A (ConA) and in the spinal cords of ORY-2001 and ORY-LSD1 treated animals, indicative of a Th2 anti-inflammatory response (Figure 2, $\mathrm{C}$ and $\mathrm{H}$ ). Pro-inflammatory cytokines like TNF-alpha were reduced by ORY-2001 and ORY-LSD1 in splenocytes induced by MOG and in the spinal cord (Figure 2, D and I). IFN-gamma was reduced in splenocytes induced by ConA with ORY-LSD1 treatment whereas in the spinal cord there were no significant changes in this parameter (Figure 2, E and J). ORY-2001 treatment increased the level of chemokine IP-10 induced by MOG but reduced MCP-1 in the periphery (Figure 2, F and G) and reduced both in the spinal cord (Figure 2, K and L). The increase of peripheral IP-10 is in accordance with the increase of cells in spleen and lymph nodes.

\section{Comparison of ORY-2001 and FTY720 at the effector stage}

The reduction of lymphocyte egress is a hallmark of the mechanism of drugs targeting the Sphingosine 1 phosphate receptors (S1PRs) like fingolimod (FTY720), a drug for the treatment of multiple sclerosis [15]. We performed a side by side comparison of the effects of ORY-2001 $(0.5 \mathrm{mg} / \mathrm{kg})$ and FTY720 $(1 \mathrm{mg} / \mathrm{kg})$ in the effector phase in the mice EAE model, at the time of the expected maximal clinical score. Both ORY-2001 and FTY720 reduced the clinical score in the model, although the cumulative disease index did not reach significance for FTY720 (Figure A2A in Additional File 3). ORY-2001 was more effective and/or faster acting than FTY720 under the test conditions (Figure 3A). The histopathological analysis revealed that ORY-2001 reduced the presence of infiltrating/demyelinating plaques in both cervical and lumbar segments, while FTY720 was less effective and reduced the number and size of demyelinating plaques in cervical 
but not lumbar segments of the spinal cord (Figure 3, B and C). In addition, ORY-2001 modulated the B cell compartment, reducing the IgG2a/lgG1 ratio in sera (Figure 3D). Both ORY-2001 and FTY720 increased the cellularity in lymph nodes but at the doses used and timepoint chosen for evaluation, only ORY-2001 increased it significantly in the spleen (Figure 3E). The CD4+ T cell fraction of the lymph node cells was increased by treatment with both drugs (Figure A2B in Additional File 3) and, within this fraction, the number of naïve T cells were significantly increased (Figure A2C in Additional File 3) while no changes were observed in the memory/effector cells of treated-mice compared with the control group.

Both compounds reduced the MOG-induced proliferation of spleen cells (Figure 3F), reflecting a reduced autoimmune response. Cultivation in medium supplemented with MOG of splenocytes obtained from animals treated with ORY-2001 did not significantly modify the release of IL-4 (Figure 3G), TNF-alpha (Figure 3H) and IFN-gamma (Figure 3I), but reduced IL-2 (Figure A2D in Additional File 3) and increased the release of chemokines IP-10 (Figure 3J) and MCP-1 (Figure 3K). Lymph node cells grown in medium supplemented with MOG significantly increased IL-4 and MCP-1 (Figure A2E and $\mathrm{H}$ in Additional File 3), while IL10 and IP-10 (Figure A2, F and G in Additional File 3) showed a tendency for increase.

The situation in the periphery contrasted with that observed in the CNS. While in the spinal cords, IL-4, TNF-alpha and IFN-gamma (Figure 3, L to N) were not significantly modified, in the brain the levels of IFN-gamma, TNF-alpha and IL-6 (Figure A2, I to K in Additional File 3) were significantly reduced in the ORY-2001 and FTY720 treated animals. ORY-2001 treatment also reduced the chemokines IP-10 and MCP-1 in the spinal cord and brain (Figure 3, O and P; Figure A2, L and M in Additional File 3).

The increase of chemokines in the periphery induced by ORY-2001 in the effector phase of the disease could contribute to the reduction of lymphocyte egress observed in both spleen and lymph nodes.

Effect of ORY-2001, ORY-LSD1 and FTY720 on gene expression 
The anti-inflammatory profile of the compounds was confirmed by performing a microarray-based gene expression surveys on pooled RNA samples from spinal cord and brain of vehicle and compound-treated EAE mice.

In the sub-chronic phase, expression changes were particularly clear in the spinal cord and, in line with the comparative efficacy of the two compounds, more prominent for ORY-2001 than ORY-LSD1 (Figure 4A, Figure 5A and Figure A3A in Additional File 3). Top genes downregulated by ORY-2001 included many genes described previously to be induced in EAE, including genes involved in antigen presentation (H2-Eb1, H2-Aa, $A 2 m, B 2 m$ and others), complement factors (C3, C1qa, C1qb, C1qc), chemokines (Ccl5, Ccl8, I/1b), microglial markers (Aif1, Cd68), factors involved in the breakdown of the blood brain barrier (Lgals3) or modulation of demyelination/remyelination (Cst7, Lcn2, $M p z$ ) or neuroprotection (Wisp2) in addition to drug targets for treatment of MS or related genes (Cd52, Itgax) (Figure 4A). On the other end of the spectrum, upregulated genes included Cox1, hemoglobin chain genes, mTOR signaling factors (Ddit4, Dpys/2), ubiquitin pathway genes (Uch/1 and Rnf144) and Pou5f1, a key factor for oligodendrocyte differentiation (Figure 5A).

The inflammation process in EAE transitions from a virulent effector phase to a more tempered chronic phase. Many of the inflammation related genes upregulated in EAE and downregulated in the spinal cord after ORY-2001 treatment in the sub-chronic phase were modulated even stronger during the effector phase (Figure 4, A and E; Figure 5, A and E); e.g. Saa1, Nmes1 and Tgfbi. On the contrary, some inflammation related genes including Ccl6, Sirpb1, Irg1, Arg1, Chi3/3 and Ms4a8a are selectively induced during the early phase of symptomatic development in EAE mice [16] and were among the most potently downregulated by ORY-2001. These transcripts may originate in an Arg1+CNS myeloid population described to arise around the peak of EAE, unable to activate myelinspecific T cells, and likely arising through an adaptive shift in expression of iNOS+ cells in response to the excessive inflammatory response and damage generated in EAE mice [17]. Upregulation of Arg1 and Chi3l3, a close homologue of Chi3l1 (YKL-40) was also 
detected in mouse models for $A D$ [18]. Treatment mediated downregulation of these genes may reflect reduced immune cell infiltration and/or adaptation.

Gene expression changes induced in the spinal cord by ORY-2001 and FTY720 in the effector phase (Figure 4B and Figure 5B) were strongly correlated $(r=0.82)$ but more potent for ORY-2001, as can be deduced by the slope of the regression line reflected in the equation in Figure $6 \mathrm{~A}$ and $\mathrm{p}$ values (Table $\mathrm{A} 2$ in Additional File 1). Changes could largely, but not exclusively be explained by the reduced infiltration of immune related cells and inflammation. Apoc2, Arg1, Lyzs, Saa3, Nmes1, Saa1, Ccl6, Tgfbi, Lgals3, Sirpb1, Timp1, Cd68, Il1b, Ms4a6d, Fcer1g, H2-Ab1, and Irg1 were among the most downregulated genes.

On the other side, treatment upregulated genes with potential neuroprotective function. Meg3, Sparcl1 and Ppargc1a were the highest induced genes in spinal cord of mice treated with ORY-2001 or FTY720. PPARGC1A is an important cofactor of NRF2. Reduced neuronal PPARGC1A expression in the MS cortex was described to partly underlie mitochondrial dysfunction in MS grey matter and contribute to neurodegeneration in MS cortex. Vice versa, increased expression in astroglia was proposed to be protective [19]. Sparc/1 and Meg3 are involved in synaptic maintenance or plasticity. Sparcl1 is produced in astrocytes and promotes excitatory synapse formation in vitro and in the developing nervous system in vivo. In EAE mice, paralysis severity correlates inversely with the ratio of the Sparcl1 to Sparc transcript, a related gene which antagonizes the synaptogenic action of Sparc/1 [20]. In addition, two single nucleotide polymorphisms (SNPs), rs9998212 and rs7695558, associated with lower brain Sparcl1 gene expression, have been shown to accelerate AD pathogenesis [21]. Meg3 is a maternally expressed gene found downregulated in HD brains and regulated by REST/NRSF, a ZNF transcription factor known to recruit KDM1A and HDAC1/2 to repress its target genes [22].

Interesting differences were also observed between the treatments: ORY-2001 but not FTY720 induced Ttr and the hemoglobin chain genes $H b a-a 1$ and $H b b-b 1$ and 
downregulated Aif1, Bst2, Rgs4 and Mtap9. ORY-2001 but not FTY720 prevented the induction of Ptpn11, required for initial infiltration of pioneer CD8 ${ }^{+} \mathrm{T}$-cells into the CNS in EAE [23], of Kif1b, and of Pik3r1, associated with susceptibility to MS by GWAS [24]. ORY-2001 also preserved the expression of Ogn, a gene coding for an extra cellular matrix protein reduced during demyelination [25] in EAE and downregulated by FTY720, as were Dcn, Mpz, Grik1, and Ecrg4.

These differences were correlated with the greater damage induced by MOG in the animals treated with FTY720 than with ORY-2001, as reflected in the clinical score. Finally, we also reviewed S100a9, the biomarker induced in EAE and the main driver for our initial hypothesis that ORY-2001 could be efficacious in MS models. S100a9 was downregulated in the spinal cord by ORY-2001 in the effector phase.

In the brain, gene expression changes were less prominent than in the spinal cord but they confirmed the anti-inflammatory effect of ORY-2001, which was especially clear in the effector phase (Figure 4, C and D; Figure 5, C and D). Again, ORY-2001 was more effective reducing inflammation markers than ORY-LSD1 in the sub-chronic phase (Figure 4, F and G).

In the effector phase, gene expression changes induced in the brain in EAE mice were also similar for ORY-2001 and FTY720 $(r=0.70)$ but more potent for the first (Figure 6B). Downregulated genes included the acute phase proteins Saa1 and Saa3; genes involved in antigen presentation (H2-Eb1, H2-Ab1, H2-Aa), complement (C3), chemokines (Ccl2, Ccl5, Ccl8), cytokine signaling (Gbp2, Gbp3, Gbp6), Nmes1, TC1658796 (Mpeg1), Irgm, Serpina3n, Oasl2, Timp1, Tgfbi, Lgals3 and Cd52. A remarkable difference in the sub-chronic relative to the effector phase was the downregulation of the secretoglobin Scgb1c1, possibly associated with the remission of symptoms. Strikingly, in the effector phase both compounds potently downregulated the pituitary markers Gh, Prl, Pomc, and Cga. The same genes were upregulated in the subchronic phase, while contrastingly inflammation associated markers remained downregulated. KDM1A has been shown to be directly involved in the control of these 
genes during pituitary development, where opposing KDM1A recruiting complexes function initially in their developmental activation and later in their repression [26]. Regulation of $\mathrm{Gh}$ is particularly interesting since $\mathrm{GH}$ has been suggested to influence the function of the immune system and Gh deficient mice do not develop EAE [27], and initial downregulation may thus be relevant to limit the damage.

The only clear difference between FTY720 and ORY-2001 in the effector phase was the induction of Cox1 by FTY720 and not by ORY-2001, although Cox1 was also upregulated by ORY-2001 and ORY-LSD1 in the sub-chronic phase.

A subset of markers identified in the microarray surveys was selected for validation by qRT-PCR on individual samples from spinal cord and brain. The mean expression values in individual samples, represented as $-\Delta \Delta C_{p}$ (Figure $6, C$ and $\left.D\right)$ or $-\Delta \Delta C_{t}$ values (Figure $\mathrm{A} 3, \mathrm{H}$ and $\mathrm{I}$ in Additional File 3), largely confirmed the regulation of the biomarkers observed in the microarray survey, although statistical significance $(p<0.05)$ was not always reached for the individual genes. For example: in the effector phase ORY-2001 downregulated the inflammatory biomarkers Cc/6, Saa3, Aif1 and Gbp2 in the spinal cord (Figure 6C); in the sub-chronic phase Cc/5, Ip10 and Tnf-alpha (Figure A3H in Additional File 3). Saa3, Aif1 and Gbp2 were also significantly downregulated by ORY-2001 in the brain in the effector phase (Figure 6D) and $C c / 5$, Ip10 and Gbp2 also in the sub-chronic phase (Figure A3, I in Additional File 3).

Gh, Prl and Pomc were downregulated in the brain of treated mice in the effector phase, although only $\mathrm{Prl}$ and Pomc reached significance. All three genes exhibited highly heterogeneous expression in individual vehicle treated samples but homogeneously low expression levels in treated samples in the effector phase. It is known that release of Gh and Prl in plasma occurs in non-synchronized short-lasting bursts [28]. The volatility of Gh and Prl expression levels may have contributed to the high variability observed in the Vehicle group, however the homogenously low levels in the treated samples suggests an effective downregulation. Upregulation of $\mathrm{Gh}$ and Prl in the sub-chronic phase was, similarly, heterogeneous. On the contrary, Ttr, found upregulated in brain, was discarded 
as a biomarker since the increased mean value resulted from the contribution of a single outlier sample.

\section{ORY-2001 and FTY720 mechanism of action}

The observation that both ORY-2001 and FTY720 reduce lymphocyte egress and provoke highly similar gene expression changes in brain and spinal cord opens the possibility that their mechanisms of action could be related. FTY720 becomes phosphorylated in vivo by the sphingosine kinases SPHK1 and SPHK2 and then acts as an S1P receptor antagonist by binding to the S1P receptor and provoking its internalization and degradation. While FTY720-P $(0.3 \mu \mathrm{M})$ acts both as an agonist [29] and antagonist [30] in GPCR based impedance assays in cells expressing the S1P1 receptor, neither ORY-2001 $(10 \mu \mathrm{M})$ nor ORY-LSD1 $(10 \mu \mathrm{M})$ showed any activity in these assays (Figure 7, A and B). Nuclear S1P and FTY720-P were reported to act as direct inhibitors of HDAC1/2 [31,32], proteins participating with KDM1A in transcription regulatory complexes. In theory, this could help to explain why FTY720-P and ORY-2001 produce highly similar effects. However, we were unable to confirm that FTY720 (0.1-3 $\mu \mathrm{M})$ or FTY720-P $(0.1-3 \mu \mathrm{M})$ had any significant impact on recombinant or cellular HDAC activity (Figure 7, C and D).

\section{ORY-2001 protects motoneurons from chronic excitotoxic stress}

In MS, glutamate (Glu)-induced excitotoxicity is a candidate downstream mechanism for neuronal injury. Threo- $\beta$-hydroxyaspartate (THA) induced organotypic spinal cord explants are used as a model of chronic excitotoxicity. THA blocks glutamate transporters, provoking a toxic increase of glutamate and intraneuronal $\mathrm{Ca}(2+)$, leading to motoneuron death. The neuroprotective effect of ORY-2001 (5, 25 and $125 \mathrm{nM})$ and control compound riluzole $(5 \mu \mathrm{M})$ was studied by co-treatment of the explants with THA and subsequent analysis of survival of SMI32 positive motoneurons. ORY-2001 protected the motoneurons from chronic excitotoxic stress at all doses tested and outperformed the control compound (Figure 8, A to E). 


\section{ORY-2001 reduces the clinical score in the TMEV model of multiple sclerosis}

To further confirm the potential of ORY-2001 for treatment of MS we tested ORY-2001 in a second established preclinical model for the disease, the Theiler's murine encephalomyelitis virus (TMEV) model. Six weeks old mice were infected with Daniel's strain of TMEV in the cerebral parenchyma and treated orally with 0.3 or $1.0 \mathrm{mg} / \mathrm{kg}$ of ORY-2001 during two weeks following onset of symptoms, at day 72 after induction (Figure 9A). Body weight, clinical score and motor function were evaluated, and histopathological analysis performed. ORY-2001 significantly improved symptomatology associated with intracranial TMEV infection and reduced the clinical score, assessed as the area under the curve (Figure 9B), while it did not produce any body weight changes. ORY-2001 significantly improved the motor activity reflected by significant changes in the horizontal activity (Figure 9C) and increased other motor activities although not significantly such as rotarod test and vertical activity (Figure 9, D and E) and reduced the cell infiltration score (Figure 9F). The infiltration of $\mathrm{CD}^{+}$and $\mathrm{CD} 8^{+} \mathrm{T}$ cells in the spinal cord, increased by TMEV infection, was significantly reduced by ORY-2001 (Figure 9, G and $H$ ). Furthermore, ORY-2001 significantly reduced microglial activation (AIF-1 positive cells; Figure 9I), increased axon integrity (NF-H; Figure 9J) and limited astroglial activation (VIM and GFAP positive cells; Figure 9K) in the spinal cord of TMEV mice, although the latter did not reach significance $(p=0.177)$. 


\section{Discussion}

Despite decades of research, the etiology of MS is still unclear. Epidemiological studies suggest that part of the missing heritability and etiology of MS could be explained by epigenetics. Histone modifying enzymes are emerging as epigenetic targets of special interest for the development of novel therapies for patients with MS [33]. For example, HDAC inhibitors have been reported to cause a shift in dominance from the Th1 to Th2 lymphocyte phenotype, to expand anti-inflammatory Tregs, and to modulate the expression of cytokines like IL10 [34]. Chromatin remodeling mediated by the H3K27me2/3 demethylase KDM6B is important in the acquisition of the M2-macrophage phenotype [35]. The KDM6 inhibitor GSK-J4 has been described to inhibit Th17 cell differentiation in vitro [36] and to promote Tregs [37]. No role had been described so far, however, for the H3K4me1/2 demethylase KDM1A in MS.

Vafidemstat (ORY-2001) is an orally bioavailable, brain penetrant KDMA1 inhibitor that rescues cognitive function in SAMP8 mice and modulates the expression of the alarmin S100a9 [9], an inflammatory biomarker upregulated in several CNS diseases with inflammatory component, including MS [10].

Here we have shown that in the EAE model, vafidemstat reduces lymphocyte egress, inflammation and clinical score. Similarly, in the Theiler virus model, it decreases the TMEV clinical score, reduces lymphocyte infiltration of immune cells in the spinal cord and microglial activation, and improves axon integrity by preventing demyelination. The efficacy of vafidemstat in the EAE model is driven by KDM1A inhibition. In the subchronic phase, treatment with vafidemstat reduced the MOG-induced proliferation of spleen cells and production of TNF-alpha and MCP-1 in vitro but did not importantly affect the $\alpha-C D 3$ induced response showing that vafidemstat does not provoke general immune-suppression. Spleen cells or lymph node cells isolated in the effector phase from animal treated with vafidemstat showed significant increase of chemokines IP-10 and MCP-1 involved in lymphocyte mobilization and inflammatory infiltration but the same chemokines were reduced in the spinal cord and brain. In the effector phase, 
vafidemstat also increased the levels of the anti-inflammatory cytokine IL-4 in lymph node cells and reduced the inflammatory cytokines IL-2 in spleen cells and IFN-gamma, TNF-alpha and IL-6 in the brain. Vafidemstat reduced the ratio of IgG2a to IgG1 MOGselective autoantibodies, indicative of a Th2 response activation [38]. These results indicate that treatment with vafidemstat reduced the CNS inflammatory milieu at the peak of $\mathrm{EAE}$.

Vafidemstat recapitulates the main therapeutic and molecular effects of the MS drug FTY720. Nevertheless, both compounds have very different targets. FTY720 is phosphorylated and binds to the S1P receptors in the cell membrane of lymphocytes, inducing receptor internalization and degradation, and immune-modulator effects [39]. Nuclear FTY720-P produced by SPHK2 [40] has been reported to inhibit HDAC1 and HDAC2 (30), proteins that participate in transcription regulatory complexes with KDM1A, targeted by vafidemstat. Although we were not able to confirm inhibition of HDACs by FTY720-P, another MS drug, dimethylfumarate (DMF), was reported to downregulate the expression of HDAC1/2 and increase NRF2 signaling $[41,42]$. The broad spectrum HDAC inhibitor VPA ameliorates clinical signs in EAE [43] and more recently T cellspecific deletion of HDAC1 was proven to prevent EAE [44]. Together, these data point at a convergence of the mechanism of action on an epigenetic hub with a central role for the KDM1A/RCOR1/HDAC1/2 complex.

Direct comparison of FTY720 and vafidemstat revealed the latter was more effective and/or faster acting in the effector phase of the EAE model. The most potently downregulated spinal cord marker in vafidemstat versus vehicle treated EAE mice was Chi3I3, a close homologue of Chi3l1 (YKL40). YKL40 is a neuroinflammation biomarker found to be increased in and/or associated with progression of patients with AD, FTD, amyotrophic lateral sclerosis, neuromyelitis optica, and multiple sclerosis. Interestingly, YKL40 levels in patients treated with vafidemstat in the AD Phase II trial ETHERAL were significantly reduced relative to placebo. 
The rapid mode of action of vafidemstat indicates that the compound may be appropriate to treat patients with acute MS flares or other inflammatory conditions, and that it may offer an alternative to corticosteroids in patients that have developed an allergy or resistance to this treatment.

Vafidemstat has inherent neuroprotective power, as illustrated by its capacity to induce the expression of neuroprotective genes and to protect motoneurons in spinal cord explants from glutamate induced excitotoxicity.

Finally, it is well known that currently used MS drugs have several undesired side effects. Vafidemstat does not target the S1PR's and is therefore not expected to induce bradycardia, effects on blood pressure, or leakage of the blood-brain barrier associated with S1PR1 modulation [45, 46, 47]. Vafidemstat treatment was effective at doses that did not significantly impact the total number of circulating lymphocytes and did not induce any signs of gastrointestinal toxicity, a side effect that has caused many patients to abandon treatment with DMF [48].

\section{Conclusions}

Vafidemstat reduces lymphocyte egress, neuroinflammation and clinical signs in MOG and TMEV induced murine models of multiple sclerosis and highlights the relevance of the KDM1A/RCOR1/HDAC1/2 epigenetic axis.

Vafidemstat has been evaluated in a Phase I trial in healthy volunteers (EUDRACT № 2015-003721-33), and significantly reduced aggression in BPD, ADHD, ASD and in moderate-severe $A D$ in the Phase lla trials REIMAGINE and REIMAGINE-AD; EUDRACT №s 2018-002140-88 and 2019-001436-54 [49,50]. Phase lla trials in mild to moderate AD (ETHERAL; EUDRACT № 2017-004893-32 and ETHERAL-US; NCT03867253) and in relapse-remitting and secondary progressive MS (SATEEN; EUDRACT № 2017-002838-23) are ongoing. Finally, based on its anti-inflammatory activity reported here and favorable safety profile, a randomized, open-label Phase II study has been initiated to evaluate the efficacy and tolerability of vafidemstat in 
combination with standard of care treatment to prevent Acute Respiratory Distress Syndrome (ARDS) in adult severely ill patients with CoVID-19 (ESCAPE; EUDRACT № 2020-001618-39).

\section{List of abbreviations}

$\mathrm{N}$ : number of biological replicates obtained from independent experiments run on different days or by different investigators; $n$ : number of technical replicas run within a single experiment. SEM: standard error of mean, SD: standard deviation.

\section{Declarations}

\section{Ethics approval and consent to participate}

All animal studies were performed according to the institutional guidelines for the care and use of laboratory animals (European Communities Council Directive 2010/63/EU) and approved by the corresponding Ethical Committees (details available in Materials and methods)

\section{Consent for publication}

Not applicable

\section{Availability of data and materials}

The microarray gene expression dataset in this manuscript has been submitted as NCBI GEO GSE118071. Raw data are available at Mendeley with doi: 10.17632/xfbnyxvw8k.1.

\section{Competing interests}

CB and TM are shareholders and executive directors of Oryzon Genomics S.A. FC, MMPL, JX, CM, PD, NS, DR are employees of Oryzon Genomics S.A. SL is a former employee of Oryzon Genomics S.A. TM, CM and DR are listed as inventors of a patent 
application of Oryzon Genomics S.A related to the content of this manuscript. EGR, MD, $\mathrm{LM}, \mathrm{CG}, \mathrm{XN}$, and $\mathrm{MH}$ have declared that no conflict of interest exists.

\section{Funding}

This study was supported by Oryzon Genomics S.A. and by RETOS: (RTC-2016-49551); EUROSTAR II: EMTherapy (CIIP-20152001/E!9683) and CDTI: EDOTEM (IDI20180117).

\section{Authors' contributions}

Conceptualization TM, FC, JX; Validation: MMPL; Formal Analysis: FC, MMPL, PD, NS; Investigation: MMPL, NS, PD, EGR, LM, DR, XN, MH; Resources: EGR, LM; Data Curation: TM, FC, MMPL; Writing Original Draft Preparation: TM, FC, JX; Writing Review \& Editing Preparation: FC, EGR, MD, LM, CG, MMPL, JX, CM, SL, PD, NS, DR, XN, MH, CB; Visualization: TM, FC, MMPL, NS, PD; Supervision: TM, FC, CM; Project Administration: TM, JX, CG; Funding Acquisition: TM, CB, JX.

\section{Acknowledgements}

Not applicable

\section{Author information}

TM: ORCID 0000-0001-5104-6867 


\section{References}

1. Trojano M and Amato MP. Multiple sclerosis in 2017: Progress in multiple sclerosis — from diagnosis to therapy. Nat Rev Neurol. 2018;14(2):72-74.

2. Johnen A, Landmeyer NC, Bürkner PC, Wiendl H, Meuth SG, Holling H. Distinct cognitive impairments in different disease courses of multiple sclerosis- $A$ systematic review and meta-analysis. Neurosci Biobehav Rev. 2017;83:568-578.

3. Rosti-Otajärvi E, Hämäläinen P. Behavioural symptoms and impairments in multiple sclerosis: a systematic review and meta-analysis. Mult Scler. 2013;19(1):31-45

4. Küçükali $C$, Kürtüncü $M$, Çoban $A$, Çebi $M$, Tüzün E. Epigenetics of multiple sclerosis: an updated review. Neuromolecular Med. 2015;17(2):83-96.

5. Andlauer TF, Buck D, Antony G, Bayas A, Bechmann L, Berthele A, et al. Novel multiple sclerosis susceptibility loci implicated in epigenetic regulation. Sci Adv. 2016;2(6):e1501678.

6. Upadhyay G, Chowdhury AH, Vaidyanathan B, Kim D, Saleque S. Antagonistic actions of Rcor proteins regulate LSD1 activity and cellular differentiation. Proc Natl Acad Sci U S A. 2014;111, 8071-8076.

7. Maes T, Cristina Mascaró C, Ortega A, Lunardi, S, Ciceri F, Somervaille TCP, et al. KDM1 histone lysine demethylases as targets for treatments of oncological and neurodegenerative disease. Epigenomics. 2015;7(4):609-26.

8. Binda C, Newton-Vinson P, Hubálek F, Edmondson DE, Mattevi A. Structure of human monoamine oxidase $\mathrm{B}$, a drug target for the treatment of neurological disorders. Nat Struct Biol. 2002;9(1):22-6.

9. Maes T, Mascaró C, Rotllant D, Lufino MMP, Estiarte A, Guibourt N, et al. Modulation of KDM1A with vafidemstat rescues memory deficit and behavioral alterations. PLOS ONE. 2020. 15(5):e0233468. doi: 10.1371/journal.pone.0233468. 
10. Brück W, Porada P, Poser S, Rieckmann P, Hanefeld F, Kretzschmar HA, et al. Monocyte/macrophage differentiation in early multiple sclerosis lesions. Ann Neurol. 1995;38(5):788-96.

11. Björk P, Björk A, Vogl T, Stenström M, Liberg D, Olsson A, et al. Identification of human S100A9 as a novel target for treatment of autoimmune disease via binding to quinoline-3-carboxamides. PLoS Biol. 2009;7(4):e97.

12. Anderson P, Gonzalez-Rey E, O'Valle F, Martin F, Oliver FJ, Delgado M. Allogeneic Adipose-Derived Mesenchymal Stromal Cells Ameliorate Experimental Autoimmune Encephalomyelitis by Regulating Self-Reactive T Cell Responses and Dendritic Cell Function. Stem Cells Int. 2017;2017:2389753.

13. Carrillo-Salinas FJ, Mestre L, Mecha M, Feliú A, Del Campo R, N Villarrubia, et al. Gut dysbiosis and neuroimmune responses to brain infection with Theiler's murine encephalomyelitis virus. Sci Rep. 2017;7:44377.

14. Turvey ME, Koudelka T, Comerford I, Greer JM, Carroll W, Bernard CCA, et al. Quantitative proteome profiling of CNS-infiltrating autoreactive CD4+ cells reveals selective changes during experimental autoimmune encephalomyelitis. J Proteome Res. 2014;13(8):3655-70.

15. Mehling M, Kappos L, Derfuss T. Fingolimod for multiple sclerosis: mechanism of action, clinical outcomes, and future directions. Curr Neurol Neurosci Rep. $2011 ; 11(5): 492-7$.

16. Wasser B, Pramanik G, Hess M, Klein M, Luessi F, Dornmair K, et al. Increase of Alternatively Activated Antigen Presenting Cells in Active Experimental Autoimmune Encephalomyelitis. J Neuroimmune Pharmacol. 2016;11(4):721732.

17. Giles DA, Washnock-Schmid JM, Duncker PC, Dahlawi S, Ponath G, Pitt D, et al. Myeloid cell plasticity in the evolution of central nervous system autoimmunity. Ann Neurol. 2018;83(1):131-141. 
18. Colton CA, Mott RT, Sharpe H, Xu Q, Van Nostrand WE, Vitek MP. Expression profiles for macrophage alternative activation genes in AD and in mouse models of AD. J. Neuroinflammation. 2006;3:27-39.

19. Nijland PG, Witte ME, van het Hof $B$, van der Pol S, Bauer J, Lassmann $H$, et al. Astroglial PGC-1alpha increases mitochondrial antioxidant capacity and suppresses inflammation: implications for multiple sclerosis. Acta Neuropathol Commun. 2014;2:170.

20. Blakely PK, Hussain S, Carlin LE, Irani DN. Astrocyte matricellular proteins that control excitatory synaptogenesis are regulated by inflammatory cytokines and correlate with paralysis severity during experimental autoimmune encephalomyelitis. Front Neurosci. 2015;9:344.

21. Seddighi S, Varma VR, An Y, Varma S, Beason-Held LL, Tanaka T, et al. MH, Kraut MA, Davatzikos C, Thambisetty M et al. SPARCL1 Accelerates Symptom Onset in Alzheimer's Disease and Influences Brain Structure and Function During Aging. J Alzheimers Dis. 2018;61(1):401-414.

22. Tan MC, Widagdo J, Chau YQ, Zhu T, Wong JJ-L, Cheung A, et al. The ActivityInduced Long Non-Coding RNA Meg3 Modulates AMPA Receptor Surface Expression in Primary Cortical Neurons. Cell Neurosci. 2017;11:124.

23. Luo Q, Sun Y, Gong F-Y, Liu W, Zheng W, Shen Y, et al. Blocking initial infiltration of pioneer CD8(+) T-cells into the CNS via inhibition of SHP-2 ameliorates experimental autoimmune encephalomyelitis in mice. $\mathrm{Br} J$ Pharmacol. 2014;171(7):1706-21.

24. Mahurkar S, Moldovan M, Suppiah V, O'Doherty C. Identification of shared genes and pathways: a comparative study of multiple sclerosis susceptibility, severity and response to interferon beta treatment. PLoS One. 2013;8(2):e57655.

25. Chelyshev YA, Muhamedshina YO, Povysheva TV, Shaymardanova GF, Rizvanov AA, Nigmetzyanova MV, et al. Characterization of spinal cord glial cells in a model of hindlimb unloading in mice. Neuroscience. 2014;280:328-39. 
26. Wang J, Scully K, Zhu X, Cai L, Zhang J, Prefontaine GG, et al. Opposing LSD1 complexes function in developmental gene activation and repression programmes. Nature. 2007;446(7138):882-7.

27. Shohreh R, Pardo CA, Guaraldi F, Schally AV, Salvatori R. GH, but not GHRH, plays a role in the development of experimental autoimmune encephalomyelitis. Endocrinology. 2011;152(10):3803-10.

28. Xu J, Jean-Marie Bekaert AJ-M, Dupont J, Rouve S, Annesi-Maesano I, De Magalhaes Filho CD, et al. Exploring endocrine GH pattern in mice using rank plot analysis and random blood samples. J Endocrinol. 2011;208(2):119-29.

29. Brinkmann V, Davis MD, Heise CE, Albert R, Cottens S, Hof R, et al. The immune modulator FTY720 targets sphingosine 1-phosphate receptors. J Biol Chem. $2002 ; 277(24): 21453-7$.

30. LaMontagne K, Littlewood-Evans A, Schnell C, O'Reilly T, Wyder L, Sanchez T, et al. Antagonism of sphingosine-1-phosphate receptors by FTY720 inhibits angiogenesis and tumor vascularization. Cancer Res. 2006;66(1):221-31.

31. Hait NC, Allegood J, Maceyka M, Strub GM, Harikumar KB, Singh SK, et al. Regulation of histone acetylation in the nucleus by sphingosine-1-phosphate. Science. 2009;325(5945):1254-7.

32. Hait NC, Wise LE, Allegood JC, O'Brien M, Avni D, Reeves TM et al. Active, phosphorylated fingolimod inhibits histone deacetylases and facilitates fear extinction memory. Nat Neurosci. 2014;17(7):971-80.

33. He H, Hu Z, Xiao H, Zhou F, Yang B. The tale of histone modifications and its role in multiple sclerosis. Hum Genomics. 2018;12(1):31.

34. Säemann MD, Böhmig GA, Osterreicher $\mathrm{CH}$, Burtscher H, Parolini O, Diakos C, et al. Anti-inflammatory effects of sodium butyrate on human monocytes: potent inhibition of IL-12 and upregulation of IL-10 production. FASEB J. $2000 ; 14(15): 2380-2$. 
35. Satoh T, Takeuchi O, Vandenbon A, Yasuda K, Tanaka Y, Kumagai Y, et al. The Jmjd3-Irf4 axis regulates M2 macrophage polarization and host responses against helminth infection. Nat Immunol. 2010;11(10):936-44.

36. Liu Z, Cao W, Xu L, Chen X, Zhan Y, Yang Q et al. The histone H3 lysine-27 demethylase Jmjd3 plays a critical role in specific regulation of Th17 cell differentiation. J Mol Cell Biol. 2015; 7(6):505-16.

37. Doñas C, Carrasco M, Fritz M, Prado C, Tejón G, Osorio-Barrios F, et al. The histone demethylase inhibitor GSK-J4 limits inflammation through the induction of a tolerogenic phenotype on DCs. J Autoimmun. 2016;75:105-117.

38. Mountford AP, Fisher A, Wilson RA. The profile of $\lg G 1$ and $\lg G 2 a$ antibody responses in mice exposed to Schistosoma mansoni. Parasite Immunol. 1994;16(10):521-7.

39. Choi JW, Gardell SE, Herr DR, Rivera R, Lee C-W, Noguchi K, et al. FTY720 (fingolimod) efficacy in an animal model of multiple sclerosis requires astrocyte sphingosine 1-phosphate receptor 1 (S1P1) modulation. Proc Natl Acad Sci U S A. $2011 ; 108(2): 751-6$.

40. Igarashi N, Okada T, Hayashi S, Fujita T, Jahangeer S, Nakamura S. Sphingosine Kinase 2 is a nuclear protein and inhibits DNA synthesis. J Biol Chem Nov. 2003;278(47):46832-9.

41. Kalinin S, Polak PE, Lin SX, Braun B, Guizzetti M, Zhang X, et al. Dimethyl fumarate regulates histone deacetylase expression in astrocytes. J Neuroimmunil. 2013;263(1-2):13-9.

42. Mills EA, Ogrodnik MA, Plave A, Mao-Draayer Y. Emerging Understanding of the Mechanism of Action for Dimethyl Fumarate in the Treatment of Multiple Sclerosis. Front Neurol. 2018;9:5.

43. Lv J, Du C, Wei W, Wu Z, Zhao G, Li Z, et al. The antiepileptic drug valproic acid restores $\mathrm{T}$ cell homeostasis and ameliorates pathogenesis of experimental autoimmune encephalomyelitis. J Biol Chem. 2012; 287(34):28656-65. 
44. Göschl L, Preglej T, Hamminger P, Bonelli M, Andersen L, Boucheron N, et al. A T cell-specific deletion of HDAC1 protects against experimental autoimmune encephalomyelitis. J Autoimmun. 2018; 86:51-61.

45. Camm J, Hla T, Bakshi R, Brinkmann V. Cardiac and vascular effects of fingolimod: mechanistic basis and clinical implications. Am Heart J. 2014;168(5):632-44.

46. Kaplan TB, Berkowitz AL, Samuels MA. Cardiovascular Dysfunction in Multiple Sclerosis. Neurologist. 2015;20(6):108-14.

47. Yanagida K, Liu CH, Faraco G, Galvani S, Smith HK, Burg N, et al. Size-selective opening of the blood-brain barrier by targeting endothelial sphingosine 1phosphate receptor. Proc Natl Acad Sci U S A. 2017;114(17):4531-6.

48. Schimrigk S, Brune N, Hellwig K, Lukas C, Bellenberg B, Rieks M, et al. Oral fumaric acid esters for the treatment of active multiple sclerosis: an open-label, baseline-controlled pilot study. Eur J Neurol. 2006;13(6):604-10.

49. Ramos-Quiroga JA, Bullock R, Ferrer M, Fadeuilhe C, Gutiérrez S, Richarte V, et al. 2019. Vafidemstat: An epigenetic drug with emerging therapeutic potential, composite data from three psychiatric disorders from the REIMAGINE trial. Poster presentation at the CINP International Meeting, October 3-5 2019, Athens, Greece.

50. Bullock R, Abdelnour C, Gutierrez S, Xaus J, Ropacki M, Boada M, et al. Vafidemstat safety and efficacy in Alzheimer-related agitation and aggression: Phase II REIMAGINE-AD 6month data. ePoster \#668. Advances in Alzheimer's and Parkinson's therapies AAT-AD/PD'T 2020. 


\section{Figures}

A

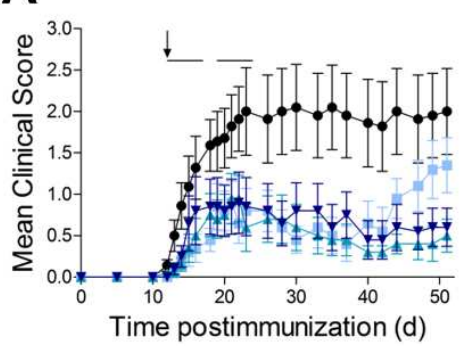

D

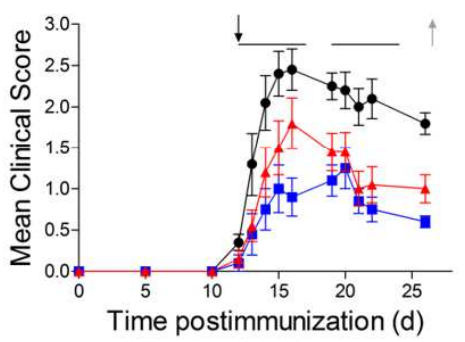

F

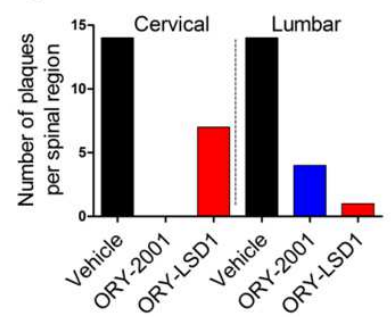

B

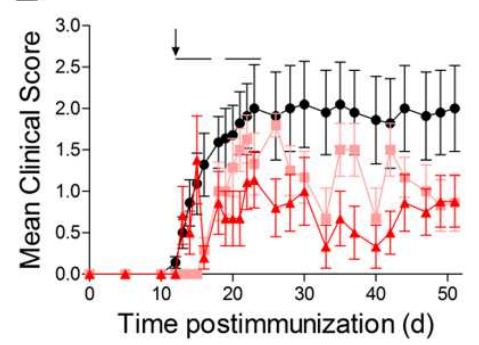

C

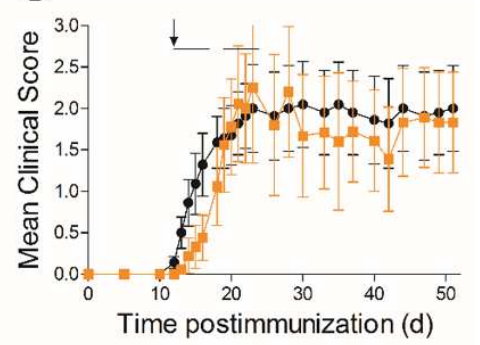

E

Cervical Sections-26d

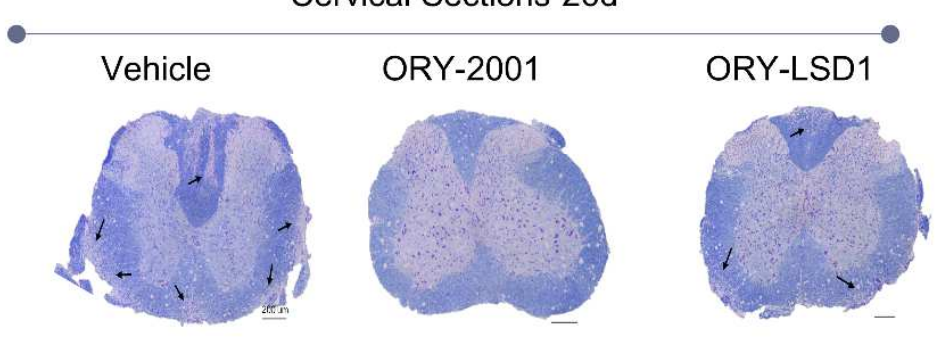

G

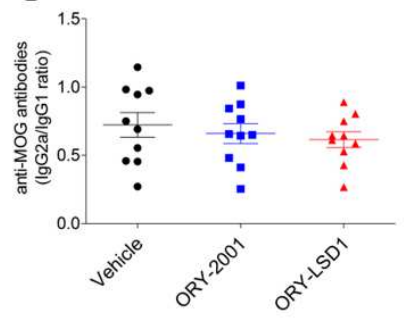

H

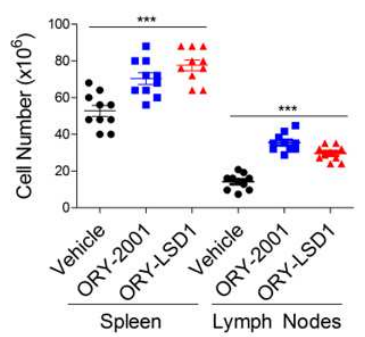

Figure 1. Therapeutic effects of LSD1 and MAO-B inhibitors in EAE mice

(A-C) The clinical score of EAE mice during the chronic phase was monitored before, during, and after two weeks of treatment (five consecutive days per week) in A with • (black) Vehicle, ORY-2001 (blue) at $0.05 \mathrm{mg} / \mathrm{kg}, \boldsymbol{\Delta} 0.5 \mathrm{mg} / \mathrm{kg}$ and $\boldsymbol{\nabla} 1.0 \mathrm{mg} / \mathrm{kg}$ (blue), in B with • (black) Vehicle, or ORY-LSD1 (red) at $\boldsymbol{\bullet} 0.09 \mathrm{mg} / \mathrm{kg}, \boldsymbol{\Delta} 0.18 \mathrm{mg} / \mathrm{kg}$ and in C with • (black) Vehicle and - (orange) rasagiline at $3.0 \mathrm{mg} / \mathrm{kg}$; up to day 51 post-immunization; 28 days after last dose. Black arrows indicate the initiation of administration of the compounds. (D) The clinical score of EAE mice during the sub-chronic phase was monitored before, during, and after two weeks of treatment (five consecutive days per week) with • (black) Vehicle, (blue) ORY-2001 at $0.5 \mathrm{mg} / \mathrm{kg}$ or $\boldsymbol{\Delta}$ (red) ORY-LSD1 at $0.18 \mathrm{mg} / \mathrm{kg}$, upto day 26 post-immunization; 3 days after last dose. Black and gray arrows indicate the initiation of administration of the compounds and the extraction of samples. (E) Infiltration of inflammatory cells and demyelination as seen in Kluver-Barrera stained spinal cords isolated from EAE mice after two weeks of treatment with vehicle, ORY-2001 or ORY-LSD1. Arrows point to areas of demyelination and inflammatory cell infiltration. (F) Mean number of demyelination plaques in the cervical and lumbar regions. $\mathrm{N}=3-$ 5/group (G) The effect of treatment on the anti-MOG-antibodies IgG2a/lgG1 ratio in sera. N=10/group. (H) Number of immune cells in the spleen and lymph nodes. ${ }^{\star \star *} p<0.001$ using 2 way ANOVA and Dunnett's Multiple Comparison test. 
A

B
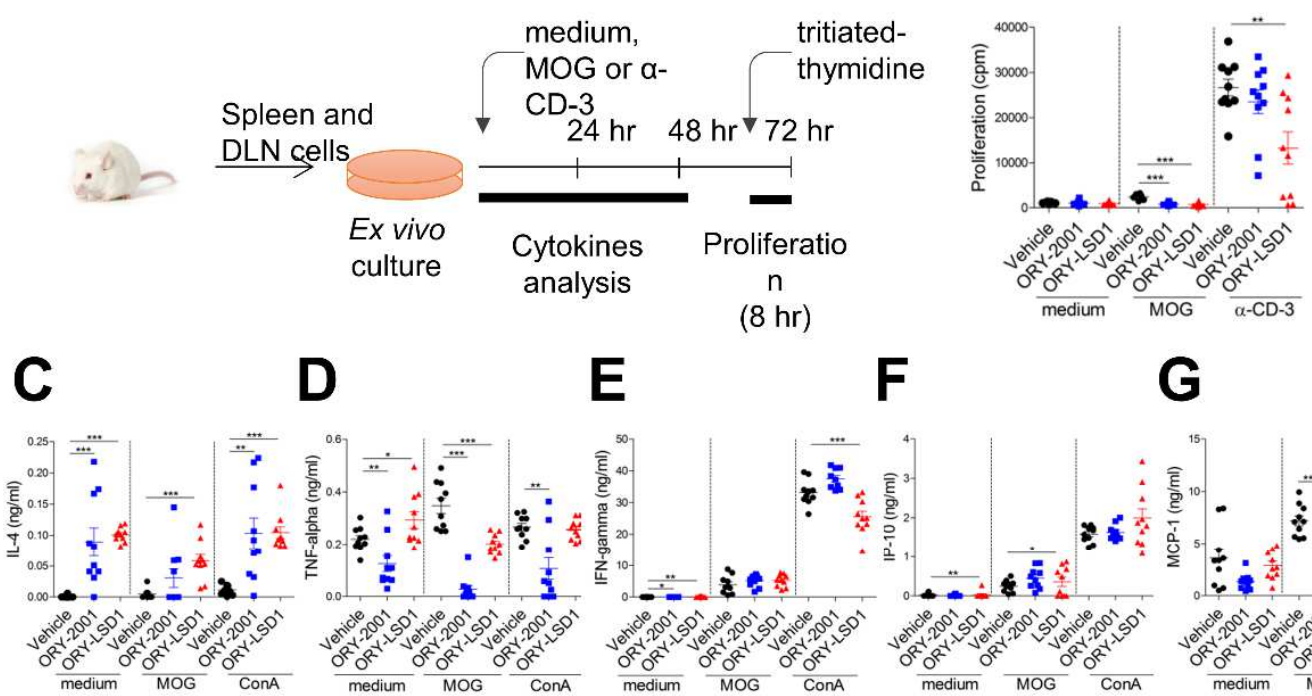

G
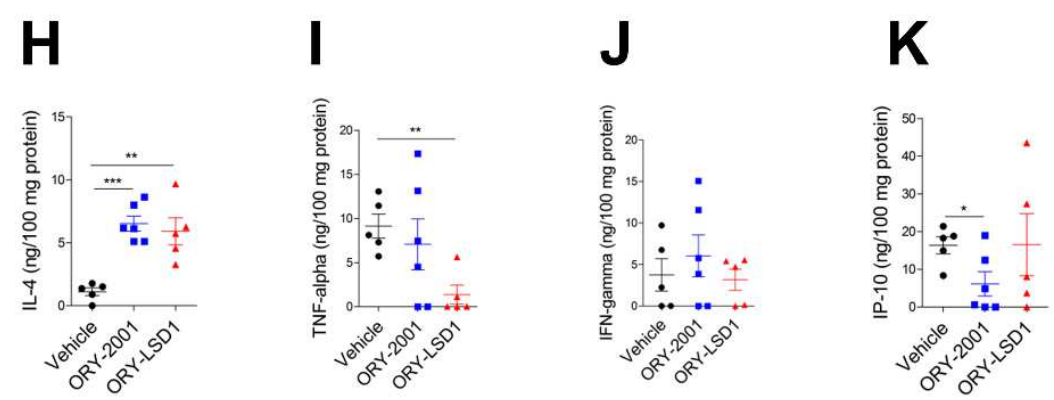

$\mathbf{L}$

Figure 2. Effects of LSD1 and MAO-B inhibitors on T cells and cytokine and chemokines release

(A) Schematic representation of the ex vivo treatment to evaluate the autoreactive response in $\mathbf{B}$ ) to $\mathbf{F}$ ). (B) Proliferation of $T$ cells from spleens of EAE mice in medium without or with MOG or a-CD3 antibody. N=6-10/group (C-G) Effect of medium with or without MOG or ConA on the release of cytokines and chemokines from spleen cells; $N=5-10 / g r o u p$. (HL) Effects of treatment on the release of cytokines and chemokines in the spinal cord; N=3-5/group. Statistical differences were indicated as vehicle vs ORY-2001 or FTY720; ${ }^{*} p<0.05 ;{ }^{* *} p<0.01 ;{ }^{* * *} p<0.001$ using the Mann-Whitney test. 
A

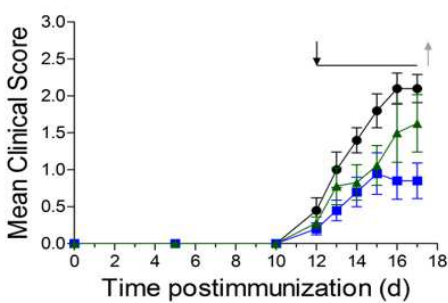

C

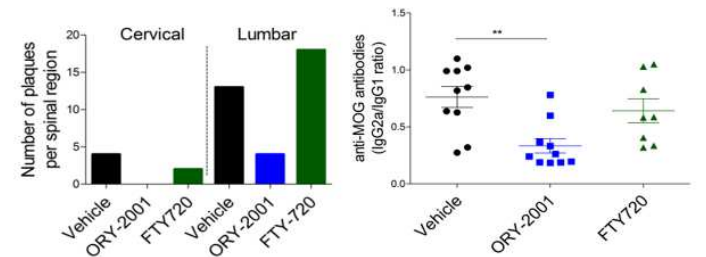

D

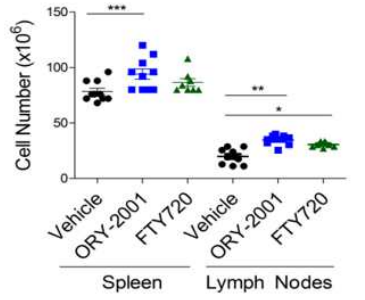

$\mathbf{E}$

Cervical Sections-17d

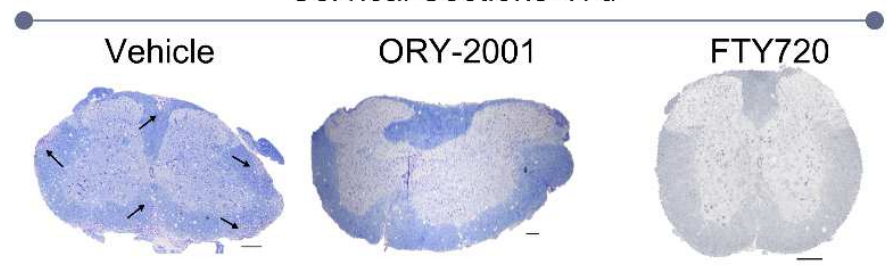

$\mathbf{F}$

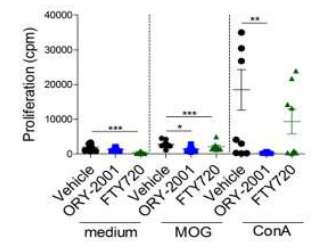

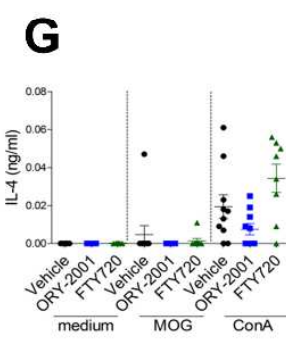

H I

J

$\mathbf{K}$

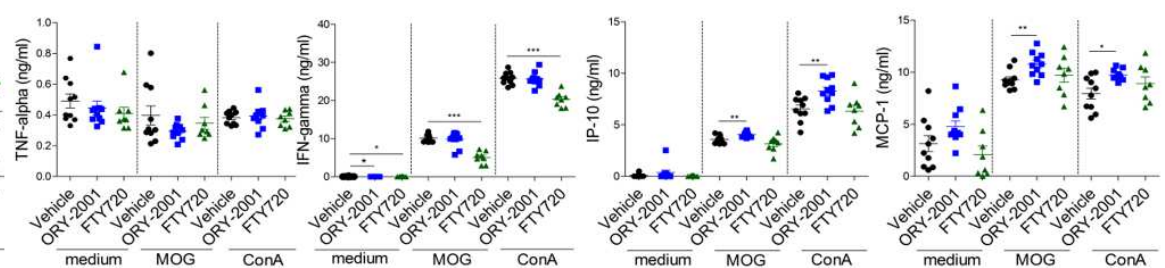

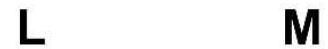

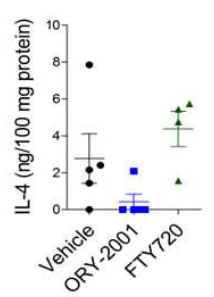

M

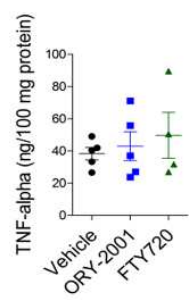

N

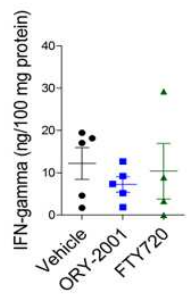

O

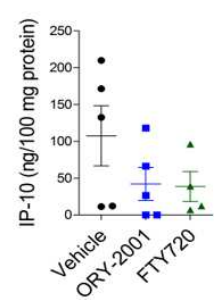

$\mathbf{P}$

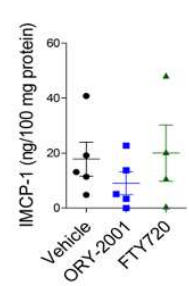

\section{Figure 3. Comparison of the effects of ORY-2001 and FTY720 in EAE mice}

The effects of treatments with • (black) Vehicle, - (blue) ORY-2001 (0.5 mg/kg) and $\boldsymbol{\Delta}$ (green) FTY720 (1 mg/kg) on EAE mice in the effector phase. Tissue collection was performed on day 17 post-immunization, after 5 days of treatment.

(A) Clinical score before and during treatment. Black and gray arrows indicate the initiation of administration of the compounds and the extraction of samples. (B) Infiltration of inflammatory cells and demyelination as seen in KluverBarrera stained spinal cords. Arrows point to areas of demyelination and inflammatory cell infiltration. (C) Mean number of demyelination plaques in the cervical and lumbar regions, N=3-5/group. (D) The effect of treatment on the anti-MOGantibodies IgG2a/lgG1 ratio in sera. N=8-10/group. (E) Number of immune cells retained in the spleen and lymph nodes. (F) Proliferation of T cells from spleens of EAE mice in medium without or with MOG or ConA. N=8-10/group; ${ }^{*} p<0.05$, ${ }^{* *} p<0.01,{ }^{* * *} p<0.001$ vs vehicle using ANOVA test. (G-K) Effects of medium with or without MOG or ConA on the release of cytokines and chemokines from spleen cells. (L-P) Effects of treatment on the release of cytokines and chemokines in the spinal cord. Statistical differences were indicated as vehicle vs. ORY-2001 or FTY720; ${ }^{*} p<0.05 ;{ }^{* *} p$ $<0.01 ;{ }^{* * *} \mathrm{p}<0.001$ using the Mann-Whitney test. 


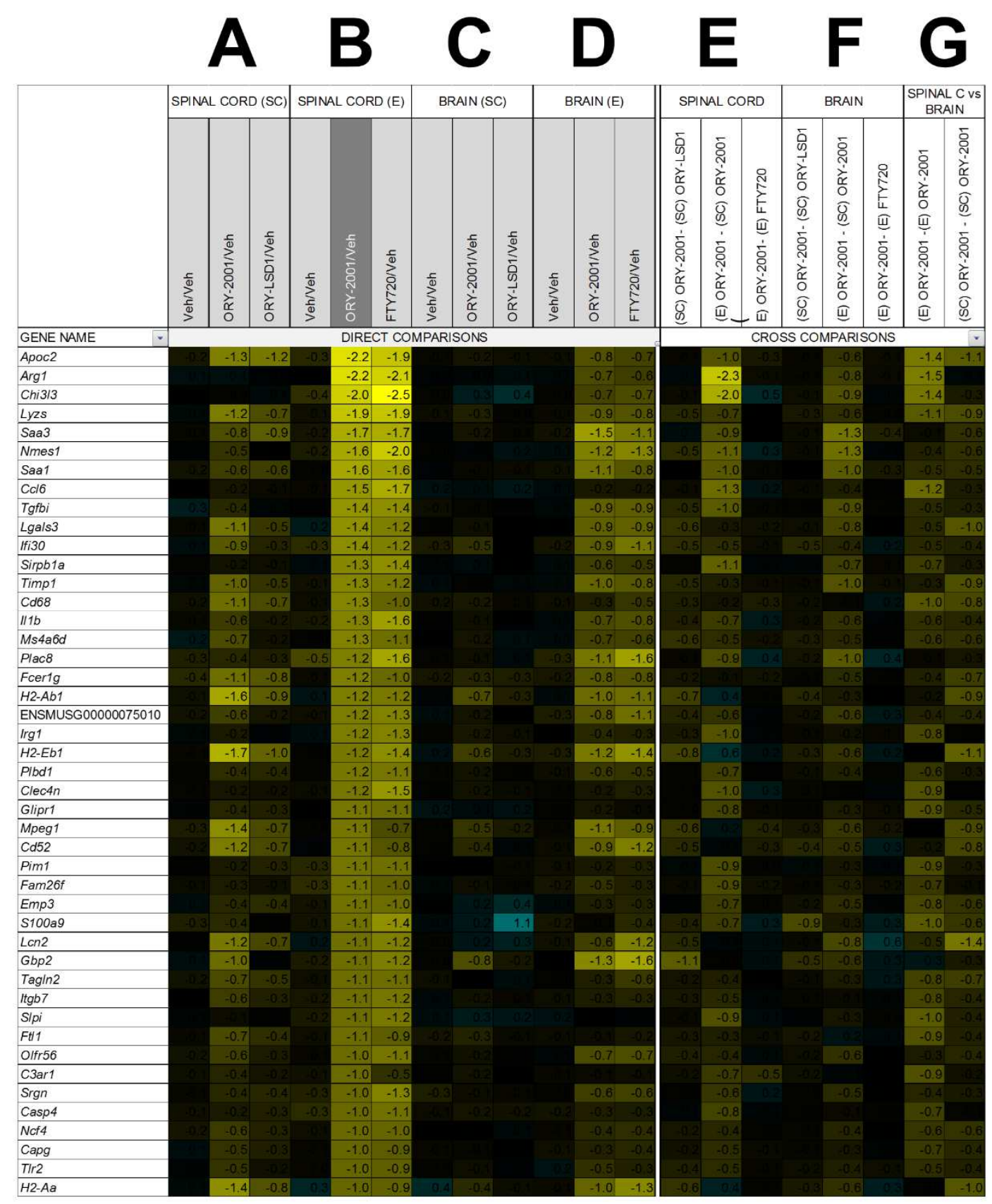

Figure 4. Genes downregulated by ORY-2001

(A) Microarray survey of gene expression changes in the spinal cord in the sub-chronic phase; 3 days after the last dose. Animals were treated with Vehicle, ORY-2001 at $0.5 \mathrm{mg} / \mathrm{kg}$ or ORY-LSD1 at $0.18 \mathrm{mg} / \mathrm{kg}$. (B) Microarray survey of gene expression changes in spinal cord in the effector phase, after treatment. Animals were treated with Vehicle, ORY-2001 at $0.5 \mathrm{mg} / \mathrm{kg}$ or FTY720 at $1 \mathrm{mg} / \mathrm{kg}$. (C) Microarray survey of gene expression changes in brain in the sub-chronic phase; 3 days after the last dose. Animals were treated with Vehicle, ORY-2001 at $0.5 \mathrm{mg} / \mathrm{kg}$ or ORY-LSD1 at $0.18 \mathrm{mg} / \mathrm{kg}$. (D) Microarray survey of gene expression changes in spinal cord in the effector phase after treatment. Animals were treated with Vehicle, ORY-2001 at $0.5 \mathrm{mg} / \mathrm{kg}$ or FTY720 at $1 \mathrm{mg} / \mathrm{kg}$. (E) Comparison of the effect of the different treatments and disease phases in the spinal cord. (F) Comparison of the effect of the different treatments and disease phases in the brain. (G) Comparison of the effects of ORY-2001 in spinal cord and brain, in both phases. Pooled RNA from N $=5$ spinal 
cords or 10 brains of vehicle, ORY-2001 or ORY-LSD1 treated mice or from $\mathrm{N}=4$ spinal cords or 6 brains of FTY720 treated mice was used to perform each survey, $n=3$ replicate probes within an array. Gene expression changes are expressed as $\log _{2}\left(\right.$ Treatment/Veh) for direct comparisons, and as the difference of the $\log _{2}($ Treatment/Veh) values for the respective conditions in the cross-comparisons. Genes downregulated $>2$ fold $\left(\log _{2}(\mathrm{ORY}-2001 / \mathrm{Veh})<-1\right)$ by $\mathrm{ORY}$ 2001 in the spinal cord in the effector phase were selected and represented for all comparisons. Veh: vehicle; SC: subchronic phase; E: effector phase. 


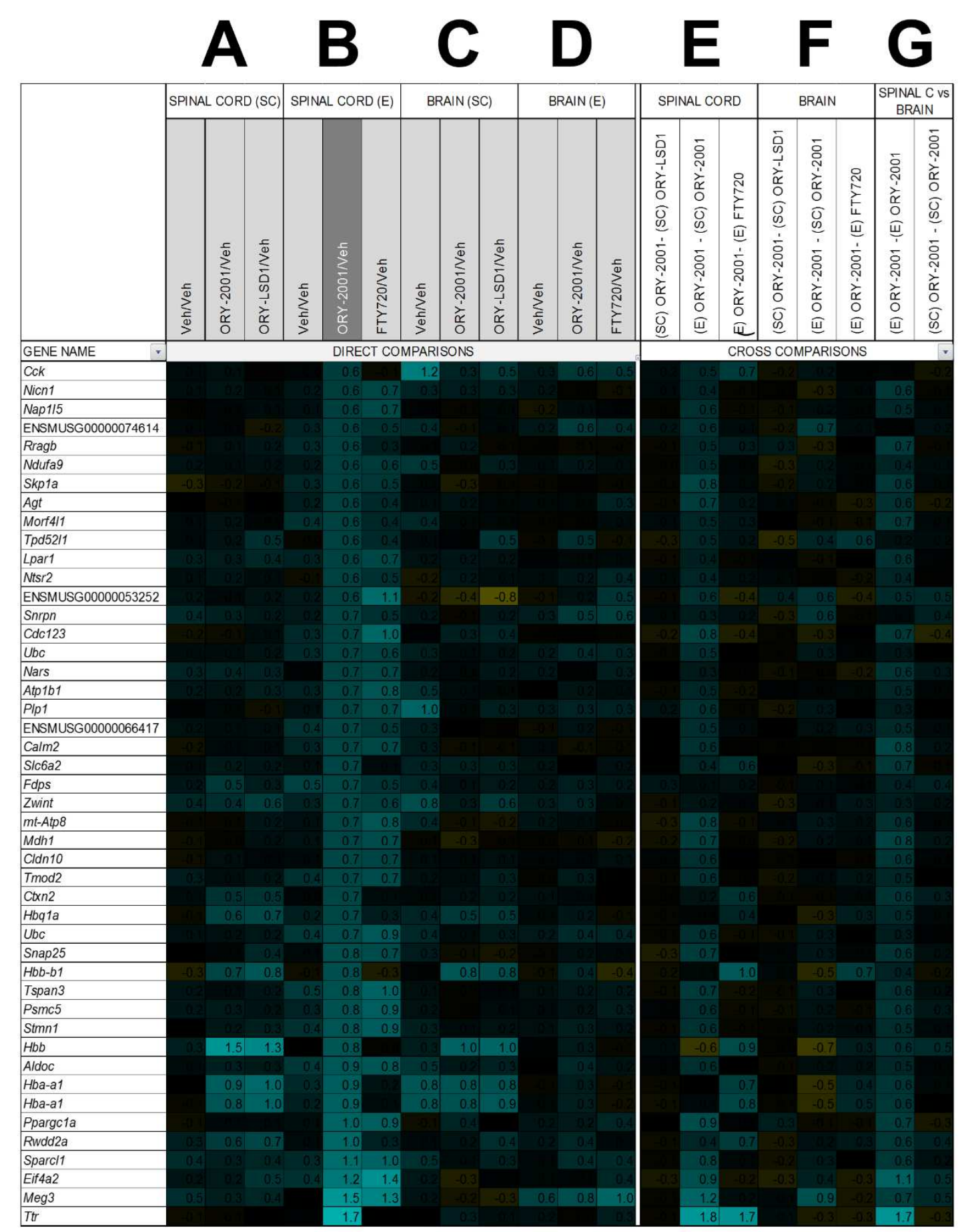

Figure 5. Genes upregulated by ORY-2001

(A) Microarray survey of gene expression changes in the spinal cord in the sub-chronic phase; 3 days after the last dose. Animals were treated with Vehicle, ORY-2001 at $0.5 \mathrm{mg} / \mathrm{kg}$ or ORY-LSD1 at $0.18 \mathrm{mg} / \mathrm{kg}$. (B) Microarray survey of gene expression changes in spinal cord in the effector phase, after treatment. Animals were treated with Vehicle, ORY-2001 at $0.5 \mathrm{mg} / \mathrm{kg}$ or FTY720 at $1 \mathrm{mg} / \mathrm{kg}$. (C) Microarray survey of gene expression changes in brain in the sub-chronic phase; 3 days after the last dose. Animals were treated with Vehicle, ORY-2001 at $0.5 \mathrm{mg} / \mathrm{kg}$ or ORY-LSD1 at $0.18 \mathrm{mg} / \mathrm{kg}$. (D) Microarray survey of gene expression changes in spinal cord in the effector phase after treatment. Animals were treated with Vehicle, ORY-2001 at $0.5 \mathrm{mg} / \mathrm{kg}$ or FTY720 at $1 \mathrm{mg} / \mathrm{kg}$. (E) Comparison of the effect of the different treatments and 
disease phases in the spinal cord. (F) Comparison of the effect of the different treatments and disease phases in the brain. (G) Comparison of the effects of ORY-2001 in spinal cord and brain, in both phases. Pooled RNA from $\mathrm{N}=5$ spinal cords or 10 brains of vehicle, ORY-2001 or ORY-LSD1 treated mice or from N = 4 spinal cords or 6 brains of FTY720 treated mice was used to perform each survey, $n=3$ replicate probes within an array. Gene expression changes are expressed as $\log _{2}\left(\right.$ Treatment/Veh) for direct comparisons, and as the difference of the $\log _{2}($ Treatment/Veh) values for the respective conditions in the cross-comparisons. Genes upregulated $>1.5$ fold $\left(\log _{2}(\mathrm{ORY}-2001 / \mathrm{Veh})>0.6\right)$ by $\mathrm{ORY}$ 2001 in the spinal cord in the effector phase were selected and represented for all comparisons. Veh: vehicle; SC: subchronic phase; E: effector phase. 
A
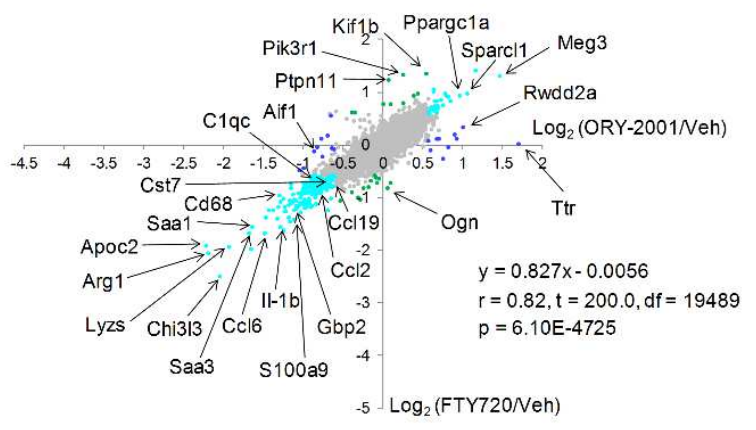

B

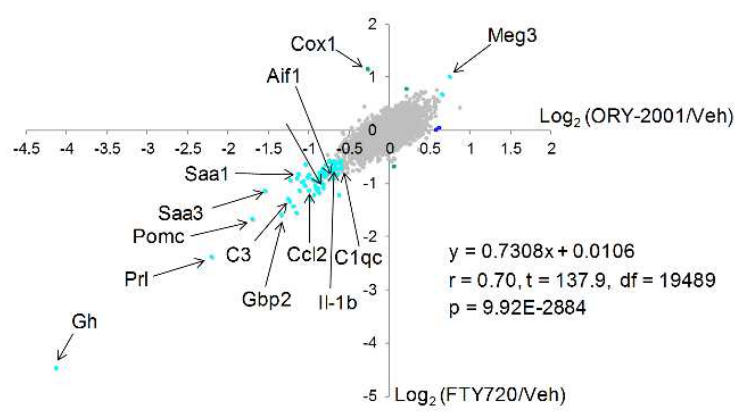

C

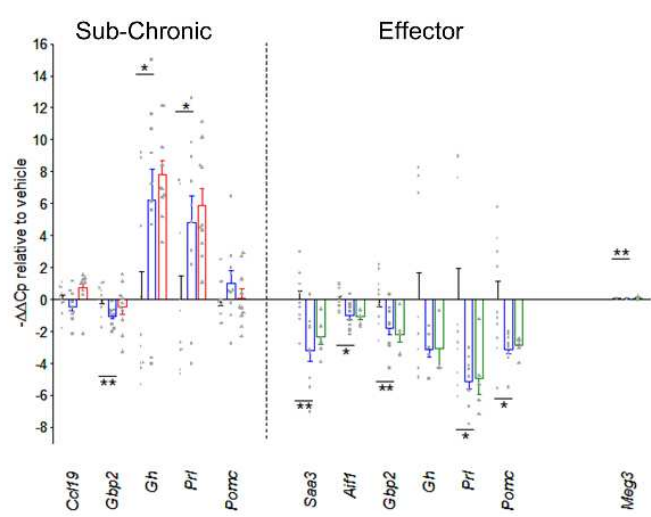

D

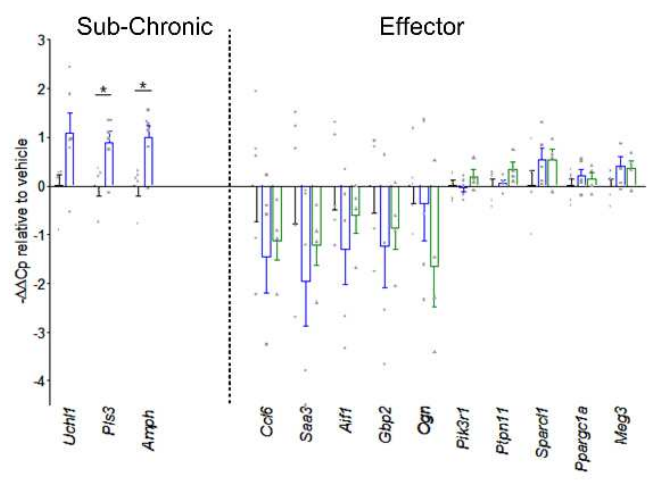

Figure 6. Comparisons of expression changes induced by ORY-2001, FTY720 and ORY-LSD1

(A-B) Genome wide comparisons of expression changes induced by ORY-2001 and FTY720 in the effector phase. A) the spinal cord or B) brain. Data are represented as scatterplots of $\log _{2}(\mathrm{ORY}-2001 / \mathrm{Veh})$ versus the $\log _{2}(\mathrm{FTY} 720 /$ Veh $)$ values. Genes regulated $>0.6$ fold are represented in blue if they are specific to ORY-2001, in green if they are specific to FTY720, in cyan if they are regulated in the same direction by ORY-2001 and FTY720. $r=$ Pearson correlation coefficient, $\mathrm{t}=\mathrm{t}$-Student test $\mathrm{t}$ value, $\mathrm{df}=$ degrees of freedom, $\mathrm{p}=$ probability of the two-tailed t-distribution for $\mathrm{t}$ and df. (C) D) QRT-PCR validations of selected individual genes modulated by ORY-2001 (blue), ORY-LSD1 (red) and FTY720 (green) in the effector phase or sub-chronic phase in $\mathbf{C}$ ) spinal cord and D) brain. Data are represented as $-\Delta \Delta \mathrm{Cp}$ values and mean \pm SEM ( $N=5-10$ mice/group, $n=3$ replicate PCRs per sample). Statistical analysis between Vehicle and ORY-2001 was calculated using the t-test. Welch's t-test was applied when the populations had unequal variances. * $p<$ $0.05 ;{ }^{* *} p<0.01$. 
A

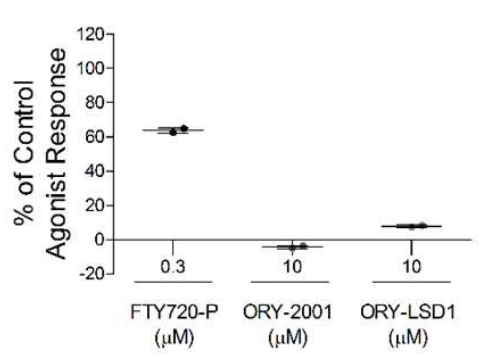

B

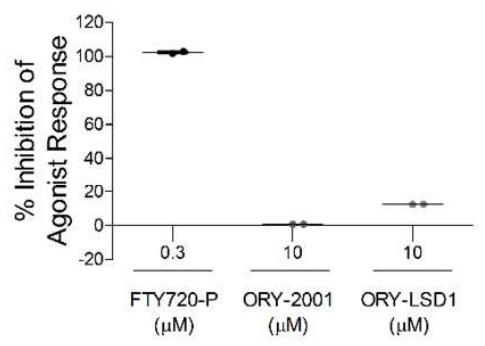

C

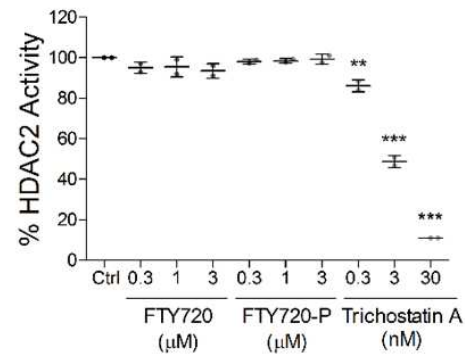

D
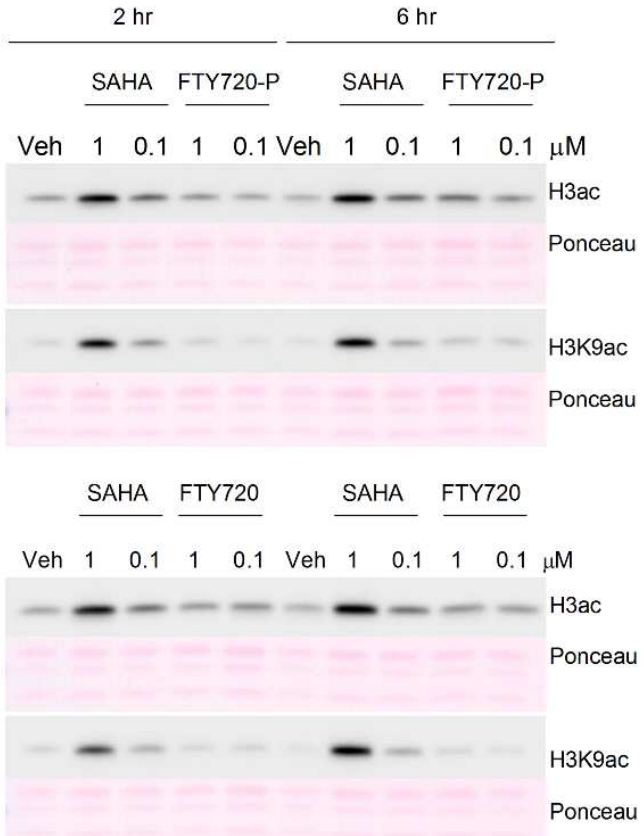

Ponceau

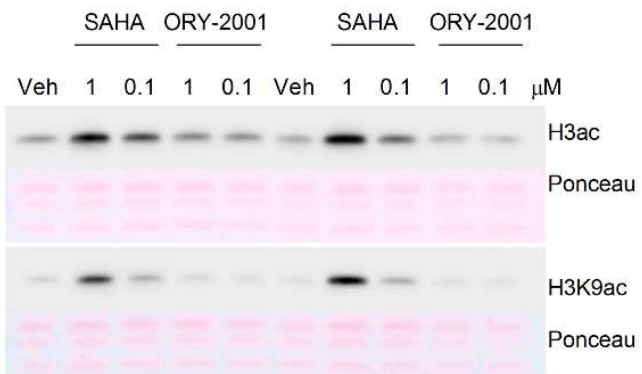

Figure 7. Effect of ORY-2001, ORY-LSD1, FTY720 and FTY720-P on S1PR and HDAC.

(A) Evaluation of the agonistic effect of the compounds on the human S1P1 receptor. Data are expressed as the percentage of the impedance response of the control agonist ( $\mathrm{S} 1 \mathrm{P}$ at $0.3 \mu \mathrm{M} ; \mathrm{EC}_{50}=0.001 \mu \mathrm{M}$ ), $\mathrm{n}=2$. (B) Evaluation of the antagonistic effect of the compounds on the human S1P1 receptor. Data are expressed as the percentage of impedance inhibition of the control agonist response ( $\mathrm{S} 1 \mathrm{P}$ at the $\mathrm{EC}_{80}=0.01 \mu \mathrm{M}$ ), $\mathrm{n}=2$. (C) HDAC2 biochemical activity. Data are expressed as percentage of control (no compound) activity, $n=2$. Statistical differences are indicated as ${ }^{* *} p<$ $0.01 ;{ }^{* *} \mathrm{p}<0.001$ using one-way ANOVA test followed by Dunnett's multiple comparison test. (D) Cellular HDAC activity assay. $\mathrm{H} 3$ acetylation ( $\mathrm{H} 3 \mathrm{ac}$ ) levels detected by Western blot analysis using global and H3K9-specific antibodies on cell extracts of SH-SY5Y cells after 2 (left) and $6 \mathrm{hr}$ (right) treatment with SAHA, FTY720-P (top), FTY720 (center) and ORY2001 (bottom) at 1 and $0.1 \mu \mathrm{M}$. Ponceau S staining was used as loading control. Veh: vehicle. 

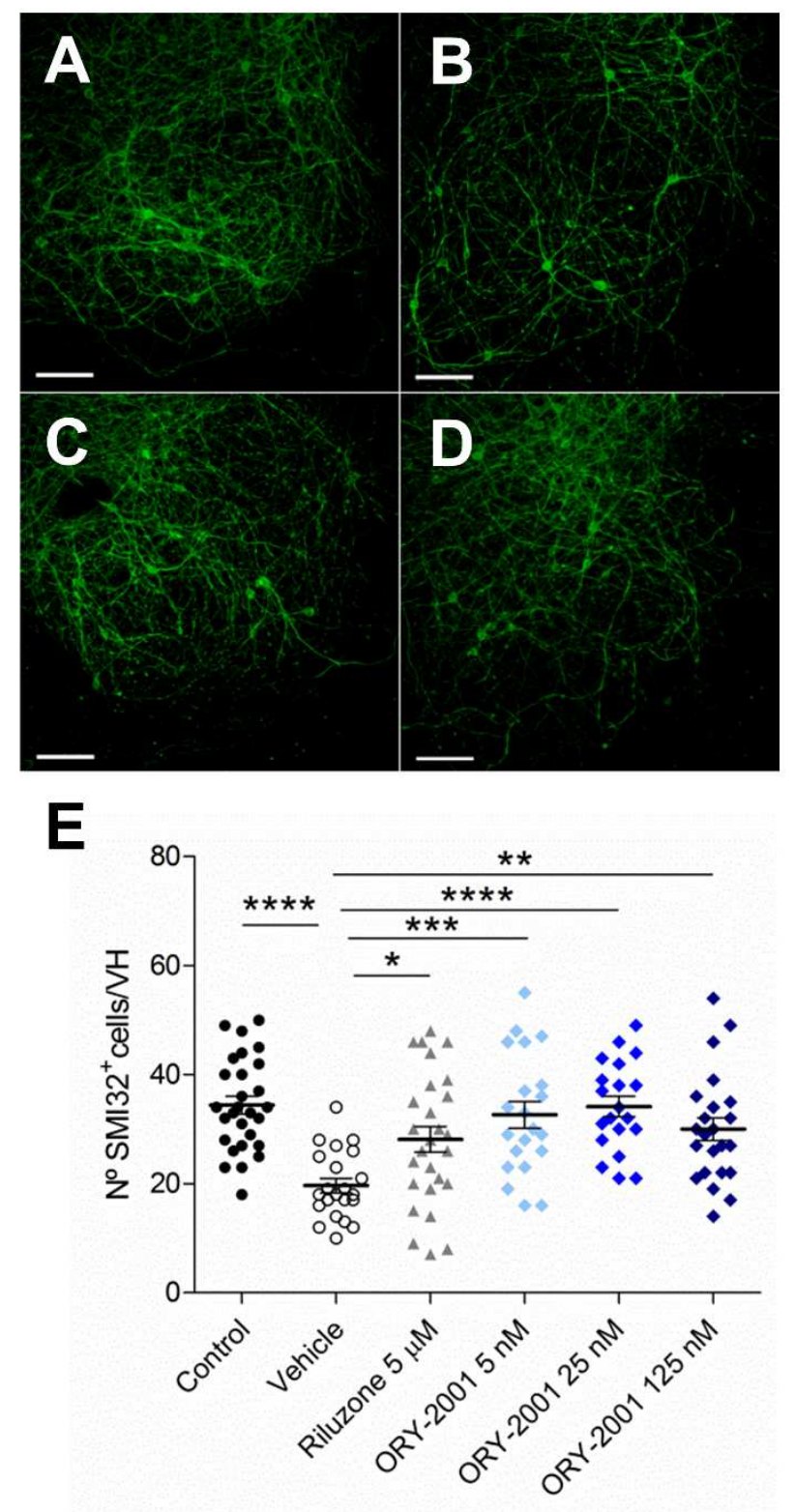

Figure 8. Effect of ORY-2001 on motoneurons injured by chronic excitotoxicity.

(A-D) SMI-32 immunohistochemistry of (A) control spinal cord explants and spinal cord explants exposed to THA treated with (B) vehicle or (C) $5 \mu \mathrm{M}$ riluzole or (D) $5 \mathrm{nM}$ ORY-2001 in a chronic excitotoxicity assay. Scale bar: $100 \mu \mathrm{m}$. (E) Quantification of SMI-32+ motoneurons in control spinal cord explants $(n=28)$ and explants exposed to THA treated with vehicle $(n=22), 5 \mu$ M riluzone $(n=27)$ or $5(n=21), 25(n=20)$ or $125 n M(n=23)$ ORY-2001. Data are pooled from 3 experiments performed on different days and presented as mean \pm SEM. Statistical significance was determined by oneway ANOVA followed by Dunnett's post hoc test of all treatments versus vehicle; ${ }^{*} p<0.05,{ }^{* *} p<0.01,{ }^{* * *} p<0.001$, ${ }^{* * *}$ $\mathrm{p}<0.0001$. 


\section{Additional Files}

File name: Additional File 1.pdf

File title: Additional Tables

File description:

Table A1: Reagents and resources

Table A2: Genome wide treatment comparison statistics

Table A3: Effect of ORY-2001 on lymphocyte count

Table A4: Primers and PCR conditions for qRT-PCR

File name: Additional File 2.pdf

File title: Additional Methods

File description:

Determination of autoantibodies of EAE mice

Determination of autoreactive response in EAE mice

RNA isolation

Oligo design, microarray fabrication and quality control

Validation of microarray biomarkers by qRT-PCR

Validation of cytokine and chemokine mediators by qRT-PCR

Protein extraction

Solubility

Biochemical assays

Cellular assays

Spinal cord explant culture and chronic excitotoxicity treatment

Processing of samples from EAE mice for histopathological analysis

Immunohistochemistry of spinal cord explants

Processing of samples from TMEV mice for histopathological analysis

EAE histopathological analysis 
Analysis of infiltration by inflammatory cells

Confocal microscopy and motoneuron quantification of the spinal cord explants

File name: Additional File 3.pdf

File title: Additional Figures

File description:

Figure A1: Therapeutic effects of ORY-2001 in EAE mice

Figure A2: Effect of treatment with ORY-2001 and FTY720 on EAE mice in the effector phase

Figure A3: Gene expression analysis of ORY-2001, ORY-LSD1, FTY720 


\section{Figures}

A

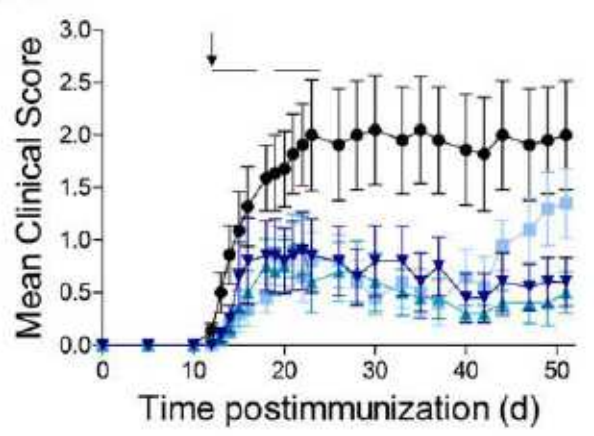

D

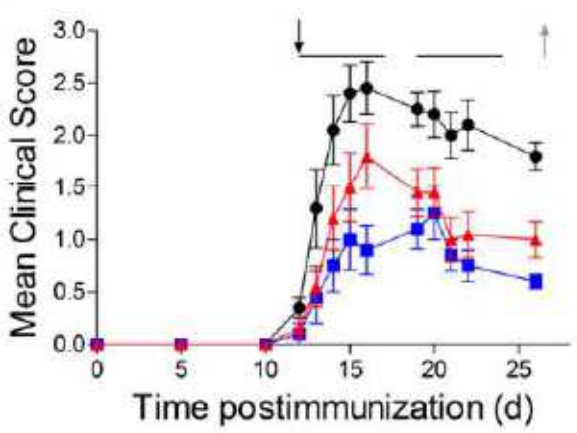

F

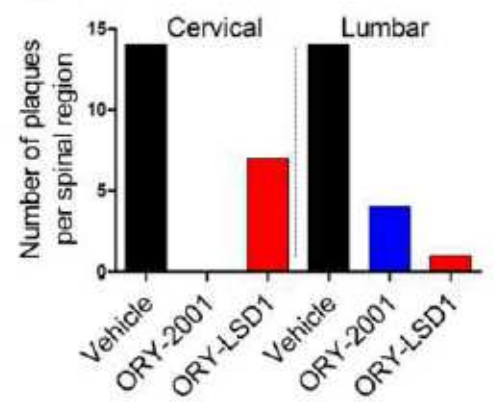

B

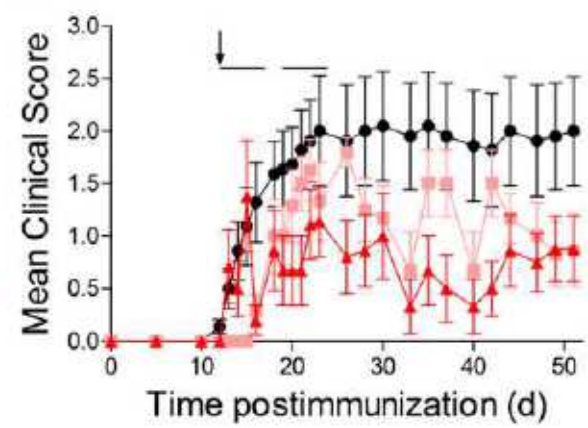

E

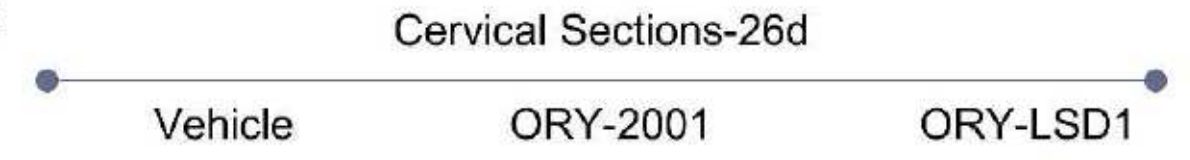

C

ORY-LSD1

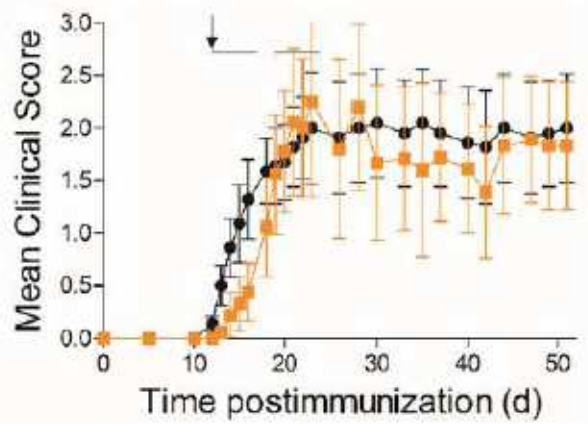

G

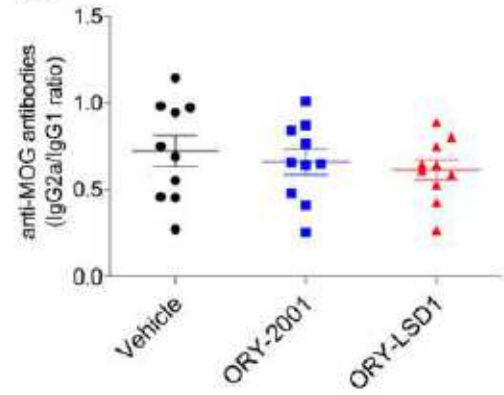

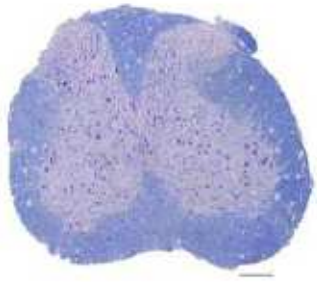

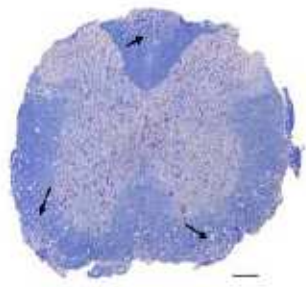

H

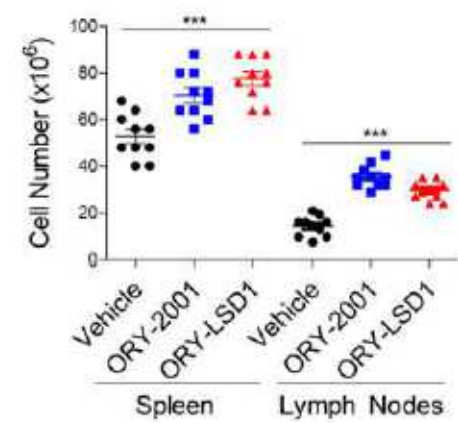

\section{Figure 1}

Therapeutic effects of LSD1 and MAO-B inhibitors in EAE mice (A-C) The clinical score of EAE mice during the chronic phase was monitored before, during, and after two weeks of treatment (five consecutive days per week) in A with $\otimes$ (black) Vehicle, ORY-2001 (blue) at $\otimes 0.05 \mathrm{mg} / \mathrm{kg}, \nabla 0.5 \mathrm{mg} / \mathrm{kg}$ and $\nabla 1.0 \mathrm{mg} / \mathrm{kg}$ (blue), in B with $\otimes$ (black) Vehicle, or ORY-LSD1 (red) at $\nabla 0.09 \mathrm{mg} / \mathrm{kg}, \nabla 0.18 \mathrm{mg} / \mathrm{kg}$ and in C with $\nabla$ (black) Vehicle and $\nabla$ (orange) rasagiline at $3.0 \mathrm{mg} / \mathrm{kg}$; up to day 51 post-immunization; 28 days after last dose. Black arrows indicate the initiation of administration of the compounds. (D) The clinical score of EAE mice during the sub-chronic phase was monitored before, during, and after two weeks of treatment (five consecutive days per week) with $\nabla$ (black) Vehicle, $\otimes$ (blue) ORY-2001 at $0.5 \mathrm{mg} / \mathrm{kg}$ or $\bigotimes($ red) ORY-LSD1 at $0.18 \mathrm{mg} / \mathrm{kg}$, upto day 26 post-immunization; 3 days after last dose. Black and gray arrows indicate the initiation of administration of the compounds and the extraction of samples. (E) 
Infiltration of inflammatory cells and demyelination as seen in Kluver-Barrera stained spinal cords isolated from EAE mice after two weeks of treatment with vehicle, ORY-2001 or ORY-LSD1. Arrows point to areas of demyelination and inflammatory cell infiltration. (F) Mean number of demyelination plaques in the cervical and lumbar regions. $N=3-5 /$ group $(G)$ The effect of treatment on the anti-MOG-antibodies IgG2a/lgG1 ratio in sera. $N=10 /$ group. (H) Number of immune cells in the spleen and lymph nodes. ${ }^{\star \star \star} \mathrm{p}$ $<0.001$ using 2 way ANOVA and Dunnett's Multiple Comparison test.
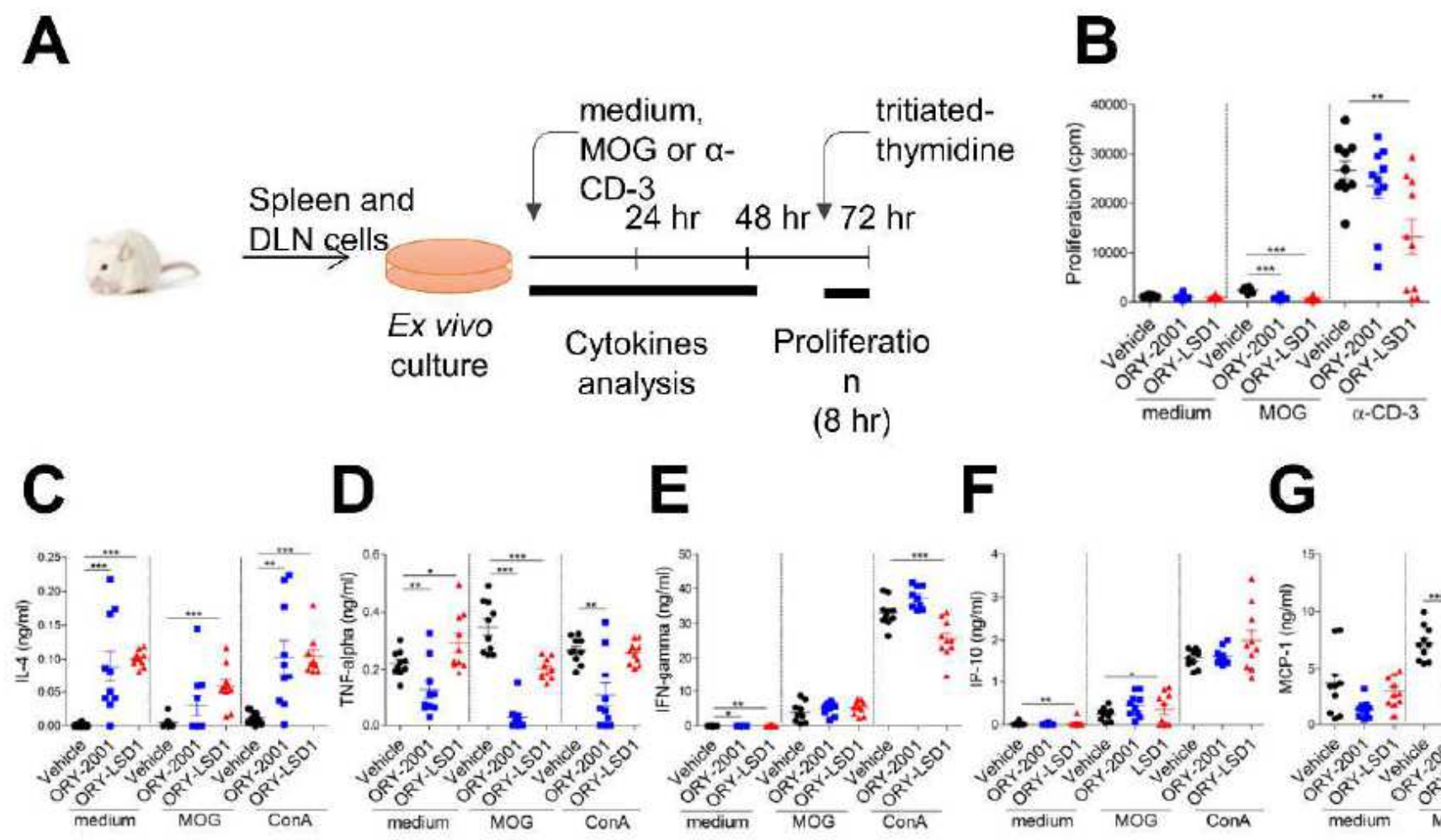

\section{H}

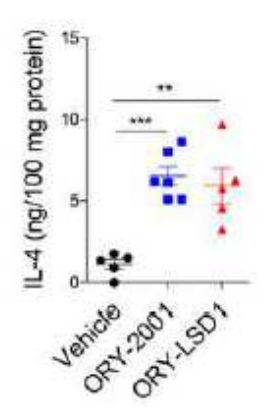

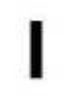

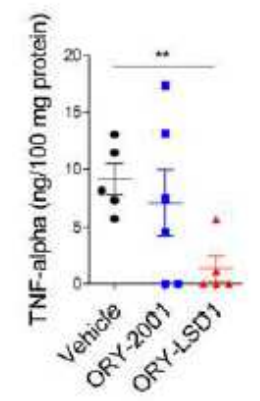

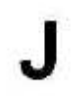

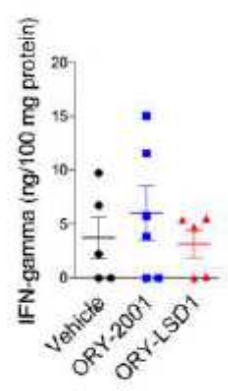

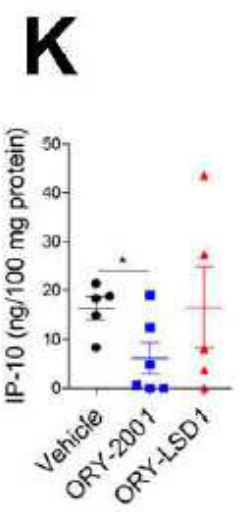
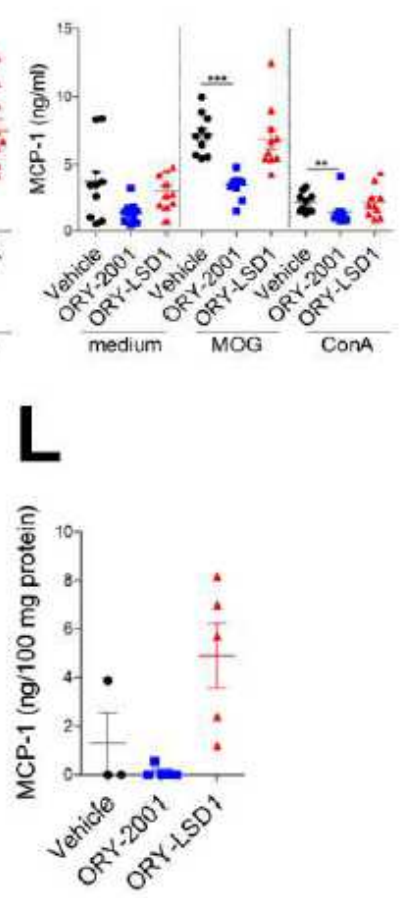

\section{Figure 2}

Effects of LSD1 and MAO-B inhibitors on T cells and cytokine and chemokines release (A) Schematic representation of the ex vivo treatment to evaluate the autoreactive response in $B$ ) to $F$ ). (B) Proliferation of $T$ cells from spleens of EAE mice in medium without or with MOG or a-CD3 antibody. N=6-10/group (CG) Effect of medium with or without MOG or ConA on the release of cytokines and chemokines from spleen cells; $N=5-10 / g r o u p$. (H-L) Effects of treatment on the release of cytokines and chemokines in the 
spinal cord; $\mathrm{N}=3-5 /$ group. Statistical differences were indicated as vehicle vs ORY-2001 or FTY720; * $<$ $0.05 ;{ }^{* \star} \mathrm{p}<0.01 ; * \star \star p<0.001$ using the Mann-Whitney test.
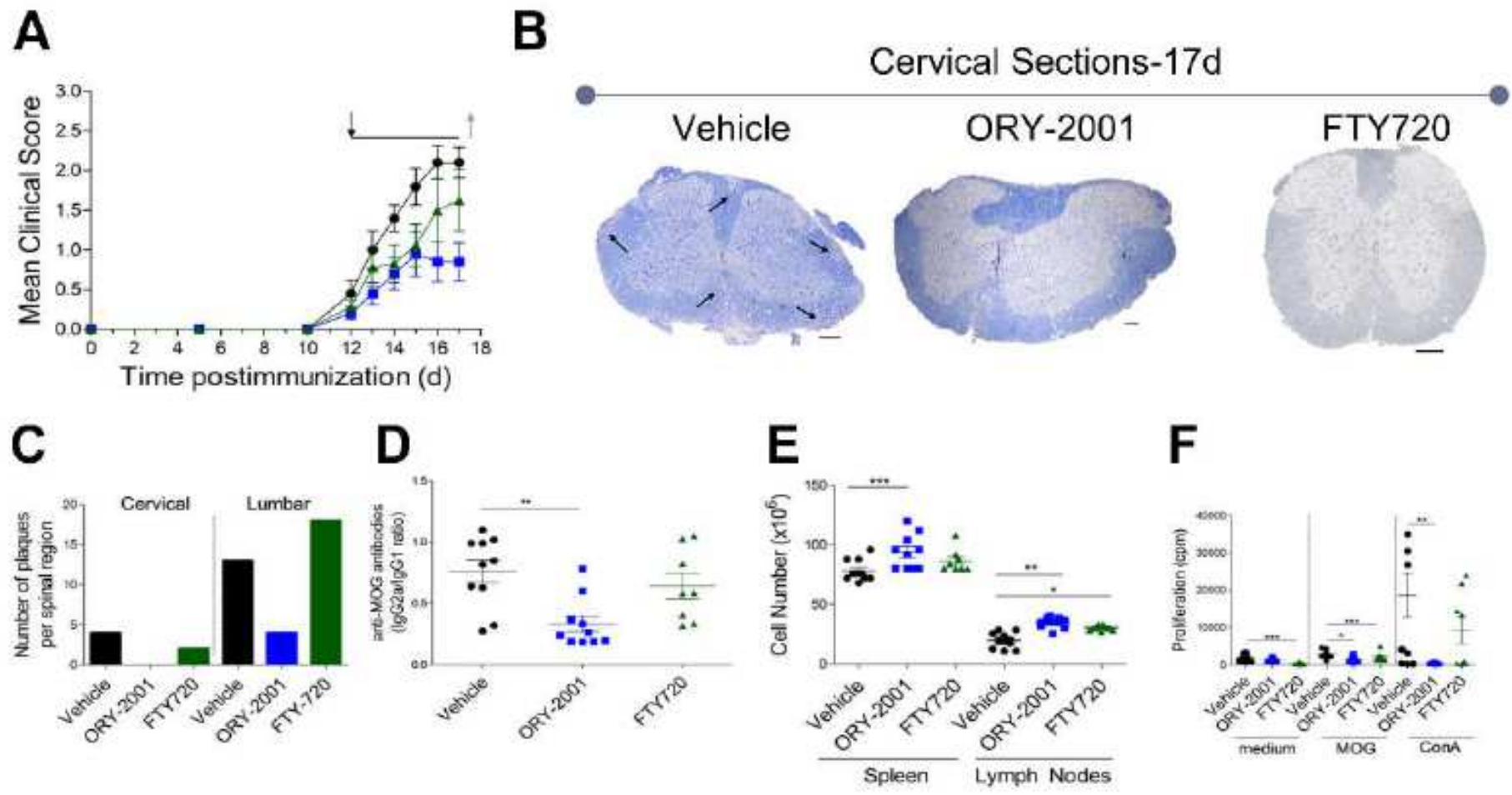

$\mathbf{F}$
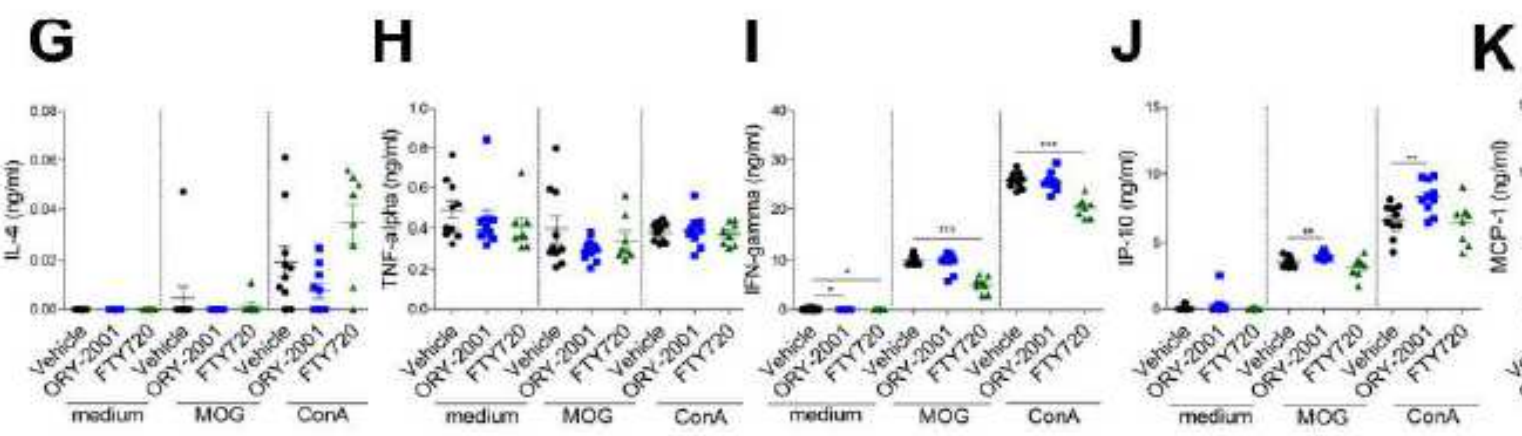

$\mathbf{L}$

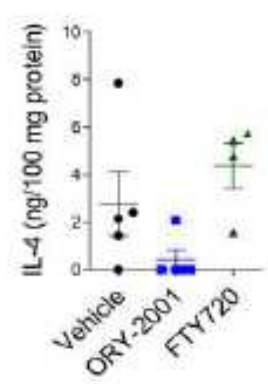

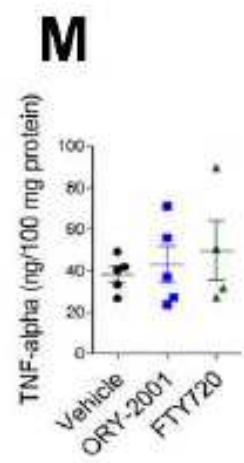
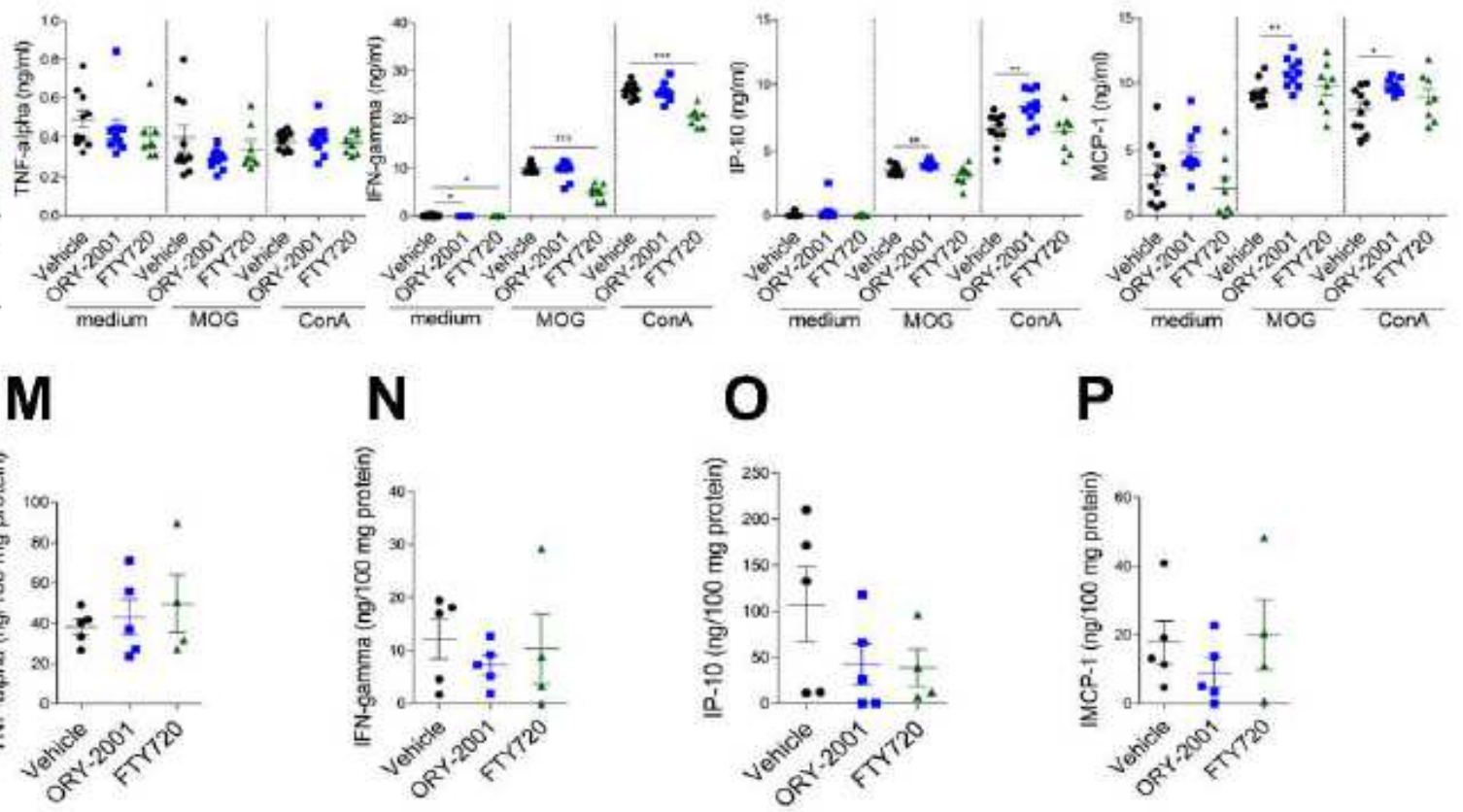

Figure 3

Comparison of the effects of ORY-2001 and FTY720 in EAE mice The effects of treatments with $\otimes$ (black) Vehicle, $\otimes$ (blue) ORY-2001 (0.5 mg/kg) and $\otimes$ (green) FTY720 $(1 \mathrm{mg} / \mathrm{kg})$ on EAE mice in the effector phase. Tissue collection was performed on day 17 post-immunization, after 5 days of treatment. (A) Clinical score before and during treatment. Black and gray arrows indicate the initiation of administration 
of the compounds and the extraction of samples. (B) Infiltration of inflammatory cells and demyelination as seen in Kluver-Barrera stained spinal cords. Arrows point to areas of demyelination and inflammatory cell infiltration. (C) Mean number of demyelination plaques in the cervical and lumbar regions, $\mathrm{N}=3-$ 5/group. (D) The effect of treatment on the anti-MOG-antibodies IgG2a/lgG1 ratio in sera. N=8-10/group. (E) Number of immune cells retained in the spleen and lymph nodes. $(F)$ Proliferation of $T$ cells from spleens of EAE mice in medium without or with MOG or ConA. N=8-10/group; ${ }^{*} p<0.05, * \star p<0.01$, $* \star * p<$ 0.001 vs vehicle using ANOVA test. (G-K) Effects of medium with or without MOG or ConA on the release of cytokines and chemokines from spleen cells. (L-P) Effects of treatment on the release of cytokines and chemokines in the spinal cord. Statistical differences were indicated as vehicle vs. ORY-2001 or FTY720; ${ }^{*} \mathrm{p}<0.05 ;{ }^{* \star} \mathrm{p}<0.01 ;{ }^{* \star *} \mathrm{p}<0.001$ using the Mann-Whitney test. 


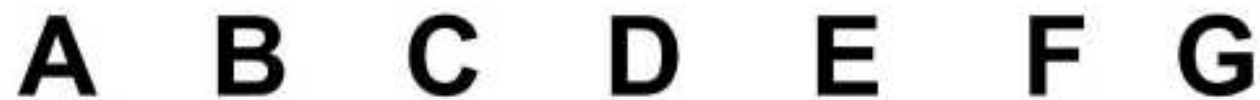

\begin{tabular}{|c|c|c|c|c|c|c|c|c|c|c|c|c|c|c|c|c|c|c|c|c|}
\hline & \multicolumn{3}{|c|}{ SPINAL CORD (SC) } & \multicolumn{3}{|c|}{ SPINAL CORO $(E)$} & \multicolumn{3}{|c|}{ BRAIN (SC) } & \multicolumn{3}{|c|}{ BRAIN (E) } & \multicolumn{3}{|c|}{ SPINAL CORD } & \multicolumn{3}{|c|}{ ERAN } & \multicolumn{2}{|c|}{$\begin{array}{l}\text { SPINAL C VS } \\
\text { BRAN }\end{array}$} \\
\hline & 虔 & 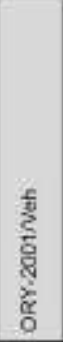 & $\frac{\frac{5}{5}}{\frac{5}{6}}$ & $\sum_{>}^{\frac{1}{6}}$ & $\frac{5}{\frac{5}{5}}$ & 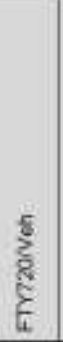 & 要 & $\begin{array}{l}\frac{5}{1} \\
\frac{2}{0} \\
\frac{d}{0} \\
\frac{2}{0} \\
\frac{c}{0}\end{array}$ & 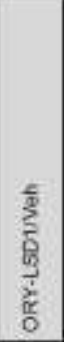 & $\frac{5}{5}$ & $\begin{array}{l}\frac{5}{3} \\
\frac{1}{8} \\
\frac{8}{8} \\
\frac{1}{8} \\
0 \\
0\end{array}$ & $\begin{array}{l}\text { है } \\
\text { है } \\
\text { है }\end{array}$ & 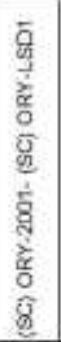 & 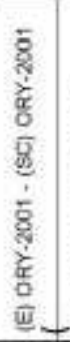 & 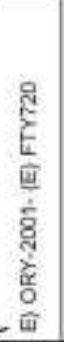 & 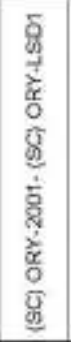 & 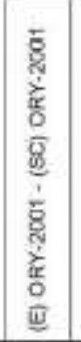 & 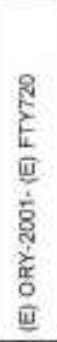 & 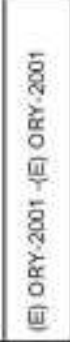 & 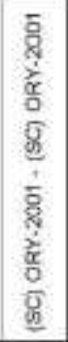 \\
\hline GENE NAME & \multicolumn{12}{|c|}{ DIRECT COMPARISONS } & \multirow{2}{*}{\multicolumn{8}{|c|}{ CAOSS COMPAFU SONS }} \\
\hline A00C2 & & -13 & -12 & & -22 & -19 & & & & & & & & & & & & & & \\
\hline Angt & & & & & -22 & -2.1 & & & & & -0.7 & & & -29 & & & 0.11 & & -1.5 & \\
\hline Chisia & & & & & -20 & 2.5 & & $x^{2}$ & [ & & कi & & & -2.0 & & & 129 & & -14 & \\
\hline Lyzs & & .12 & 07 & & .19 & .19 & & 20 & & & 00 & 41 & & क्न & & & 20 & & 11 & \\
\hline Sas 3 & & 48 & 09 & & .177 & 17 & & $2=$ & & & .15 & & & 99 & & & -10 & & & \\
\hline Nmest & & & & & -16 & -20 & & & & & -12 & .1 .3 & & -1.1 & & & .13 & & 60 & \\
\hline Saat & & ale & $A B$ & & -10 & -10 & & & & & -14 & 31 & & -10 & & & 1.10 & & & \\
\hline $\cos 6$ & & & & & .15 & 17 & & & & & & & & 1.9 & & & & & -12 & \\
\hline Tgaid & & 23 & & & .24 & .14 & & & & & 100 & 와 & & 10 & & & 영 & & & \\
\hline$\angle g a i s 3$ & & -11 & 915 & & 14 & 112 & & & & & 0.0 & 9.8 & & & & & on & & & \\
\hline$m 30$ & & 60 & $6 x$ & & -14 & -12 & & $x_{3}^{3}$ & & & -09 & +1. & & $-9 ?$ & & & & & & \\
\hline Supb 19 & & & & & -17.3 & .14 & & & & & 09 & & & -11 & & & -07 & & 9 & \\
\hline Timp1 & & .10 & 53 & & .13 &.+2 & & & & & .10 & 50 & & & & & 1.0 & & & \\
\hline $\cos 8$ & & -1.1 & 07 & & 19 & 39 & & $=$ & & & $\equiv$ & 10 & & & & & & & 10 & \\
\hline$\$ 10$ & & & & & -19 & -1.6 & & & & & .0 .7 & s. & & -67 & & & 20 & & & \\
\hline Mstasd & & 17 & & & +43 & $-\pi+1$ & & & & & | 97 & & & & & & & & & \\
\hline Pland & & & & & 1.2 & .4 .8 & & & & & .11 & $=7.6$ & & ब्राप & & & 10 & & & \\
\hline Foertg & & का1 & -98 & &.+2 & .70 & & $a^{2}$ & & & $8 \pi$ & $s$ & & & & & कas & & & \\
\hline $\mathrm{H} 2 \mathrm{Abt}$ & & -16 & 00 & & -12 & .12 & & 2127 & & & .10 & & कात & & & & & & & \\
\hline ENSMLSGC0000075010 & & 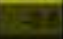 & & & .12 & -1.5 & & & & & \begin{tabular}{|l|}
.28 \\
\end{tabular} & .1 .1 & & खीन & & & (-0) & & & \\
\hline hot & & & & & -12 & .13 & & & & & & & & td & & & & & ar & \\
\hline H2.EbT & & .17 & 10 & & 12 & 14 & & 135 & & & 12 & .14 & 0 & & & & 152 & & & \\
\hline Plodt & & & & & 1.2 & 41 & & & & & 198 & & & 207 & & & 139 & & & \\
\hline Clecth & & & & & -12 & -15 & & & & & & & & 10 & & & & & 09 & \\
\hline Gopert & & & & & 111 & 411 & & & & & & & & - 세 & & & 123 & & L- 0 & \\
\hline Mpeg! & & -14 & का & & IIt & .0 .1 & & 13 & & & -11 & & Wot & & & & 120 & & & \\
\hline $\cos 2$ & & 12 & ar & & 411 & .0 .8 & & $17 a$ & & & .09 & .12 & & & & & 03 & & & \\
\hline Pimt & & & & & (2) & .71 & & & & & & & & 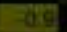 & & & & & of & \\
\hline Fam $20 \mathrm{t}$ & & & & & -21 & .40 & & & & & 05 & & & $\rightarrow 9.9$ & & & & & 07 & \\
\hline Emp3 3 & & & 24 & & -21 & +0 & & & 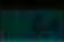 & & $t=$ & & & al & & & 105 & & or & \\
\hline STo00at & & & & & 1.1. & .1 .4 & & & 11 & & & & & air & & .00 & & & -10 & \\
\hline $\operatorname{Lan} 2$ & & .12 & 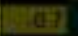 & & at & .12 & & & & & D. & $\sqrt{x}$ & & & & & 101 & & $a$ & ts \\
\hline 6092 & & -10 & & & $7+1$ & -72 & & -100 & & & -13 & -42 & 11 & & & 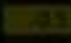 & 120 & & & \\
\hline Tagin2: & & Hag & 25 & & -1.1 & +1.1 & & & & & & & & & & & 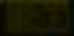 & & Ee & \\
\hline Mgb7 & & 3 & & & 1.1 & 72 & & 5 & & & & & & 28 & & & & & - 01 & \\
\hline Spa & & & & & 41 & +2 & & & & & & & & $9 \mathrm{~d}$ & & & 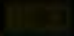 & & 10 & \\
\hline FN1 & & $\sqrt{47}$ & 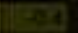 & & -21 & 00 & & 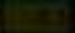 & & & $z_{2}$ & & & & & & & & -00 & \\
\hline Oarrse & & +2.8 & & & 10 & 411 & & & & & 0.2 & 4 & & 90 & & & 100 & & & \\
\hline Clart & & & & & .80 & & & & & & & & & 싀 & 7 & & -1 & & -0 & \\
\hline Sign & & 33 & & & 40 & 1.8 & & & & & -0.2 & & & 20 & & & 100 & & & \\
\hline Cosput & & & & & -90 & .11 & & & & & & & & $9 \mathrm{a}$ & & & & & Eif & \\
\hline Mad & & If & & & 19 & -10 & & & & & get & & & & & & 20 & & & \\
\hline Caps & & & & & +70 & -00 & & & & & & & & & & & & & -07 & \\
\hline $7 \times 2$ & & & & & 10 & $-0,0$ & & & & & 04 & & & & & & & & & \\
\hline $\mathrm{H2} \cdot \mathrm{Aa}$ & & -14 & 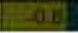 & & 4.0 & 0.0 & & 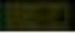 & & & 1.10 & 1. & 501 & & & & 0 & & 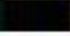 & \\
\hline
\end{tabular}

\section{Figure 4}

Genes downregulated by ORY-2001 (A) Microarray survey of gene expression changes in the spinal cord in the sub-chronic phase; 3 days after the last dose. Animals were treated with Vehicle, ORY-2001 at 0.5 $\mathrm{mg} / \mathrm{kg}$ or ORY-LSD1 at $0.18 \mathrm{mg} / \mathrm{kg}$. (B) Microarray survey of gene expression changes in spinal cord in the effector phase, after treatment. Animals were treated with Vehicle, ORY-2001 at $0.5 \mathrm{mg} / \mathrm{kg}$ or FTY720 at $1 \mathrm{mg} / \mathrm{kg}$. (C) Microarray survey of gene expression changes in brain in the sub-chronic phase; 3 days 
after the last dose. Animals were treated with Vehicle, ORY-2001 at $0.5 \mathrm{mg} / \mathrm{kg}$ or ORY-LSD1 at 0.18 $\mathrm{mg} / \mathrm{kg}$. (D) Microarray survey of gene expression changes in spinal cord in the effector phase after treatment. Animals were treated with Vehicle, ORY-2001 at $0.5 \mathrm{mg} / \mathrm{kg}$ or FTY720 at $1 \mathrm{mg} / \mathrm{kg}$. (E) Comparison of the effect of the different treatments and disease phases in the spinal cord. (F) Comparison of the effect of the different treatments and disease phases in the brain. (G) Comparison of the effects of ORY-2001 in spinal cord and brain, in both phases. Pooled RNA from N = 5 spinal cords or 10 brains of vehicle, ORY-2001 or ORY-LSD1 treated mice or from $\mathrm{N}=4$ spinal cords or 6 brains of FTY720 treated mice was used to perform each survey, $n=3$ replicate probes within an array. Gene expression changes are expressed as Log2(Treatment/Veh) for direct comparisons, and as the difference of the Log2(Treatment/Veh) values for the respective conditions in the cross-comparisons. Genes downregulated $>2$ fold (Log2(ORY-2001/Veh) <-1) by ORY-2001 in the spinal cord in the effector phase were selected and represented for all comparisons. Veh: vehicle; SC: sub-chronic phase; E: effector phase. 


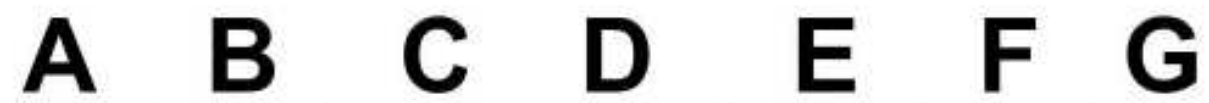

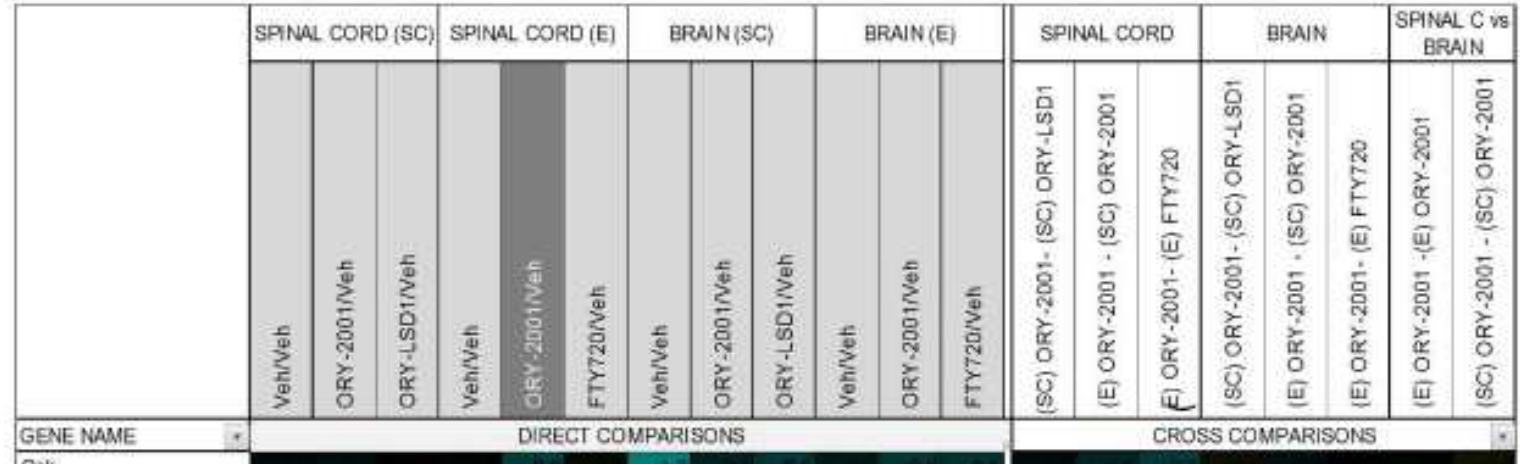

$$
\text { Cok }
$$

Niont

ENSMUUSGDODODOT 4814

Fragb

Notuas

Skpta

\begin{tabular}{|l|}
\hline Agt \\
\hline Mortsit
\end{tabular}

Tposisit

ipart

Nesr2

ENSMUSG00000053252

Snppn

Colc123

Cob

Nars

\begin{tabular}{|l|l|}
\hline Aptot \\
Pipt
\end{tabular}

ENSMUSGD00000066417

Gaim2

Sictia2

Fops

mi-Atp's

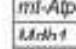

Clonto

\begin{tabular}{l} 
Trmod2 \\
\hline Ctrn2
\end{tabular}

Cann2

Hoq
Cob

Cbe

fob-ot

Tspanz

Psmo5

Simnt

Hbb
Aldoc

Hos-at

Hba-al

Paargcta

Rodd2a

Sasarcis

Eilla?

Meg3
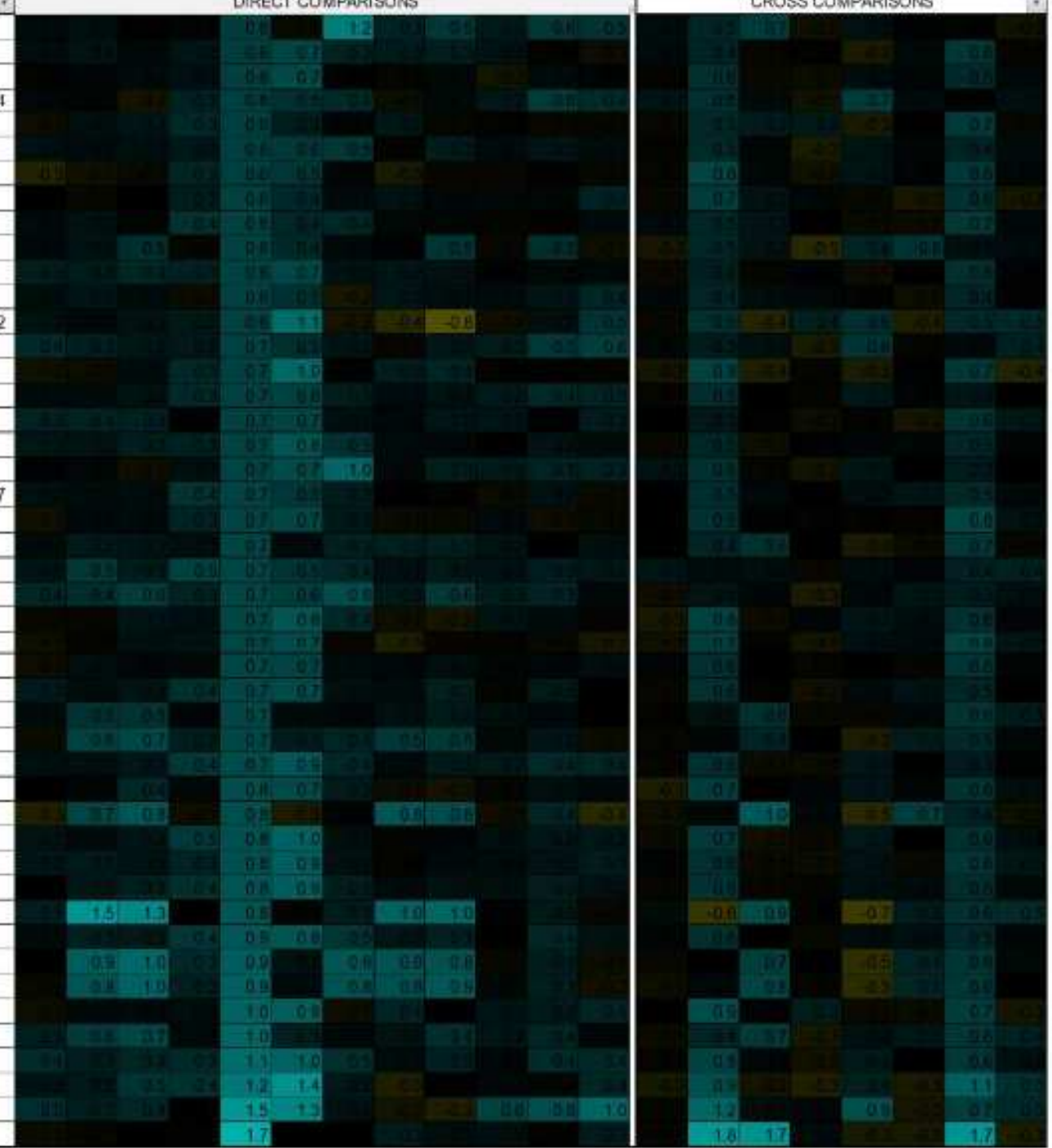

\section{Figure 5}

Genes upregulated by ORY-2001 (A) Microarray survey of gene expression changes in the spinal cord in the sub-chronic phase; 3 days after the last dose. Animals were treated with Vehicle, ORY-2001 at 0.5 $\mathrm{mg} / \mathrm{kg}$ or ORY-LSD1 at $0.18 \mathrm{mg} / \mathrm{kg}$. (B) Microarray survey of gene expression changes in spinal cord in the effector phase, after treatment. Animals were treated with Vehicle, ORY-2001 at $0.5 \mathrm{mg} / \mathrm{kg}$ or FTY720 at $1 \mathrm{mg} / \mathrm{kg}$. (C) Microarray survey of gene expression changes in brain in the sub-chronic phase; 3 days 
after the last dose. Animals were treated with Vehicle, ORY-2001 at $0.5 \mathrm{mg} / \mathrm{kg}$ or ORY-LSD1 at 0.18 $\mathrm{mg} / \mathrm{kg}$. (D) Microarray survey of gene expression changes in spinal cord in the effector phase after treatment. Animals were treated with Vehicle, ORY-2001 at $0.5 \mathrm{mg} / \mathrm{kg}$ or FTY720 at $1 \mathrm{mg} / \mathrm{kg}$. (E) Comparison of the effect of the different treatments and disease phases in the spinal cord. (F) Comparison of the effect of the different treatments and disease phases in the brain. (G) Comparison of the effects of ORY-2001 in spinal cord and brain, in both phases. Pooled RNA from N = 5 spinal cords or 10 brains of vehicle, ORY-2001 or ORY-LSD1 treated mice or from $\mathrm{N}=4$ spinal cords or 6 brains of FTY720 treated mice was used to perform each survey, $n=3$ replicate probes within an array. Gene expression changes are expressed as Log2(Treatment/Veh) for direct comparisons, and as the difference of the Log2(Treatment/Veh) values for the respective conditions in the cross-comparisons. Genes upregulated $>1.5$ fold (Log2(ORY-2001/Veh) $>0.6)$ by ORY-2001 in the spinal cord in the effector phase were selected and represented for all comparisons. Veh: vehicle; SC: sub-chronic phase; E: effector phase.
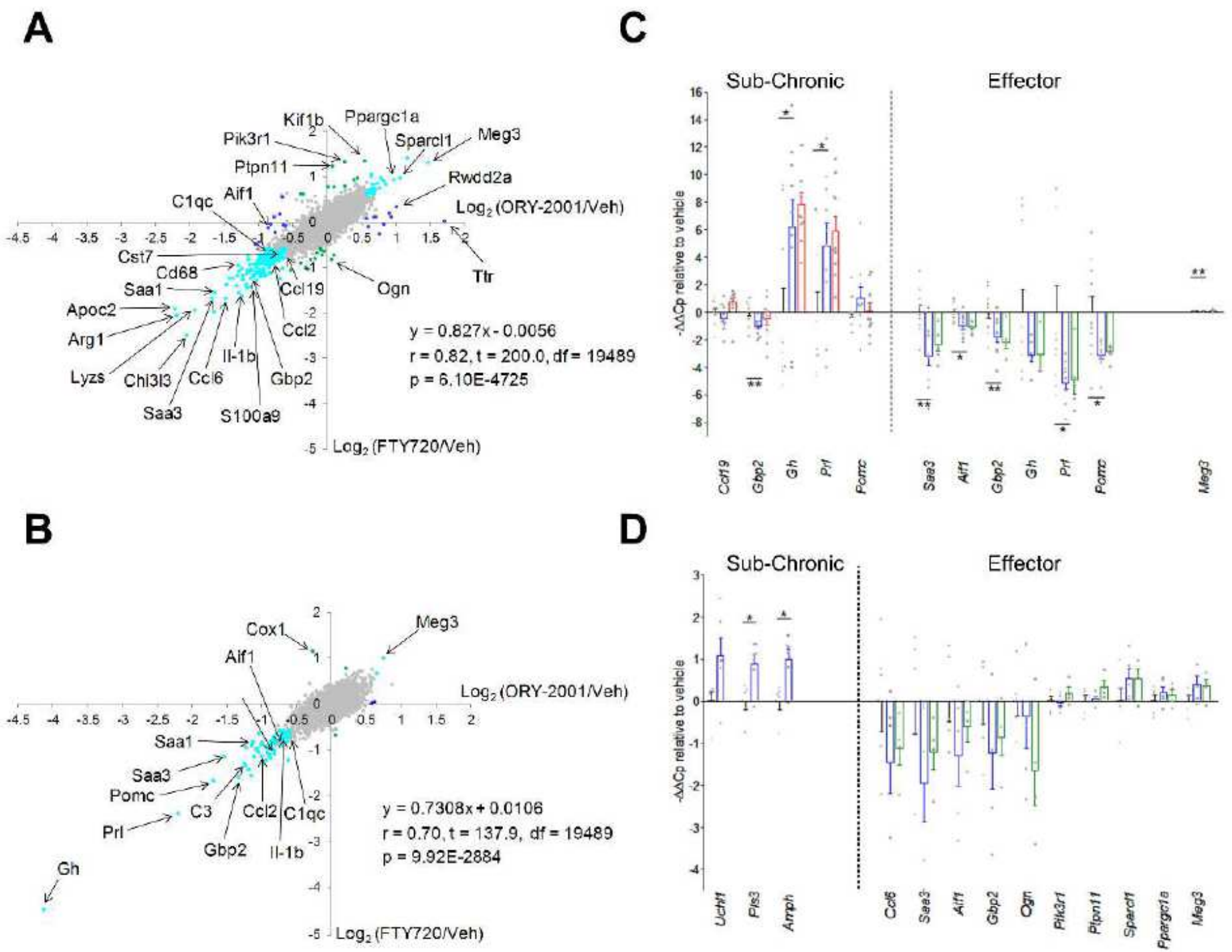

D

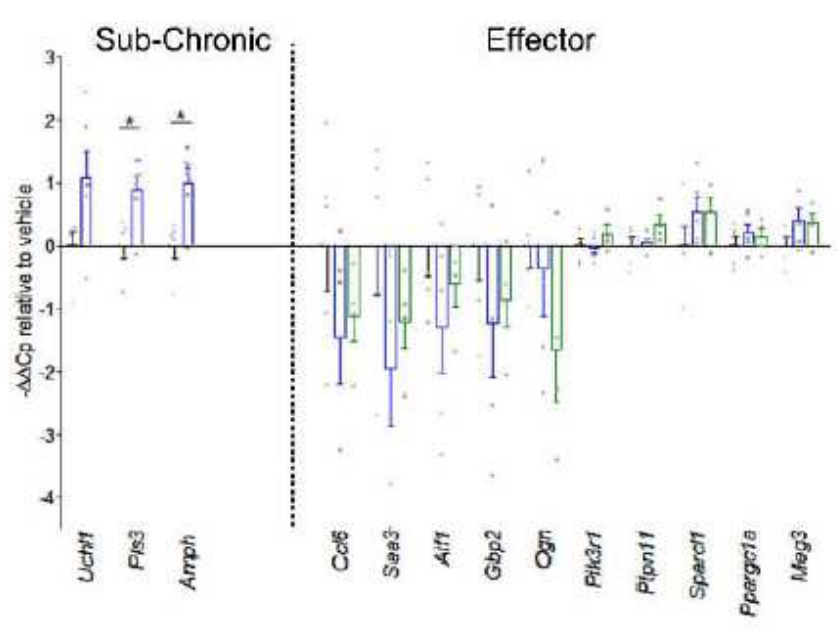

Figure 6 
Comparisons of expression changes induced by ORY-2001, FTY720 and ORY-LSD1 (A-B) Genome wide comparisons of expression changes induced by ORY-2001 and FTY720 in the effector phase. A) the spinal cord or B) brain. Data are represented as scatterplots of Log2(ORY-2001/Veh) versus the Log2(FTY720/Veh) values. Genes regulated $>0.6$ fold are represented in blue if they are specific to ORY2001 , in green if they are specific to FTY720, in cyan if they are regulated in the same direction by ORY2001 and FTY720. $r=$ Pearson correlation coefficient, $t=t$-Student test $t$ value,$d f=$ degrees of freedom, $p$ = probability of the two-tailed t-distribution for $t$ and df. (C, D) qRT-PCR validations of selected individual genes modulated by ORY-2001 (blue), ORY-LSD1 (red) and FTY720 (green) in the effector phase or subchronic phase in C) spinal cord and D) brain. Data are represented as $-\triangle \triangle C p$ values and mean $\pm S E M(N=$ 5 - 10 mice/group, $n=3$ replicate PCRs per sample). Statistical analysis between Vehicle and ORY-2001 was calculated using the t-test. Welch's t-test was applied when the populations had unequal variances. * $p<0.05 ; * \star p<0.01$
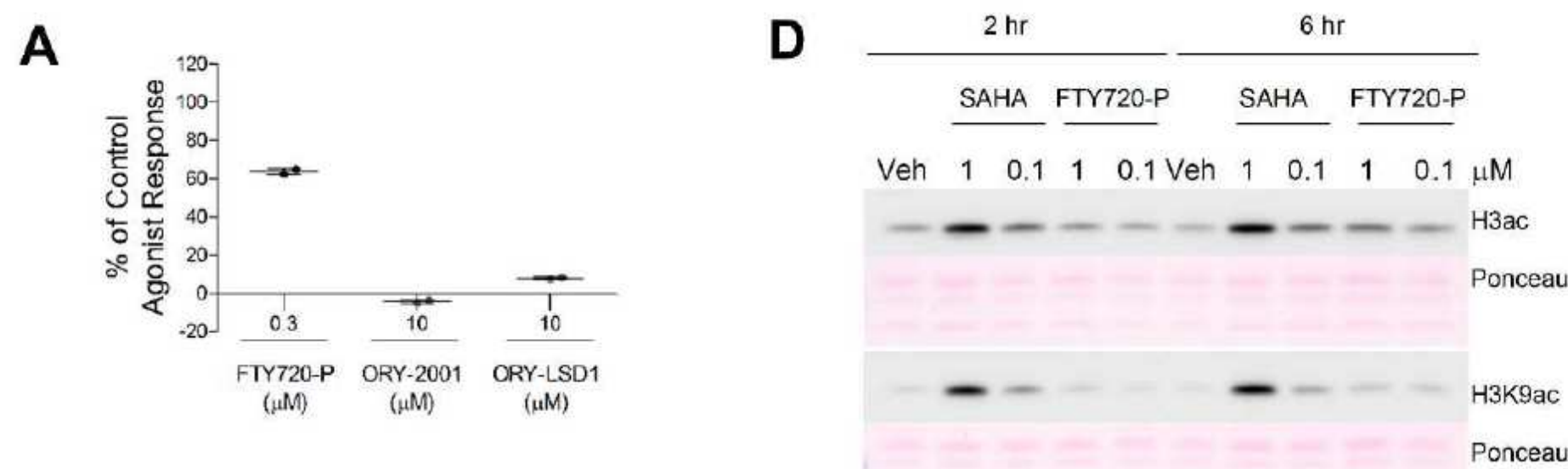

B
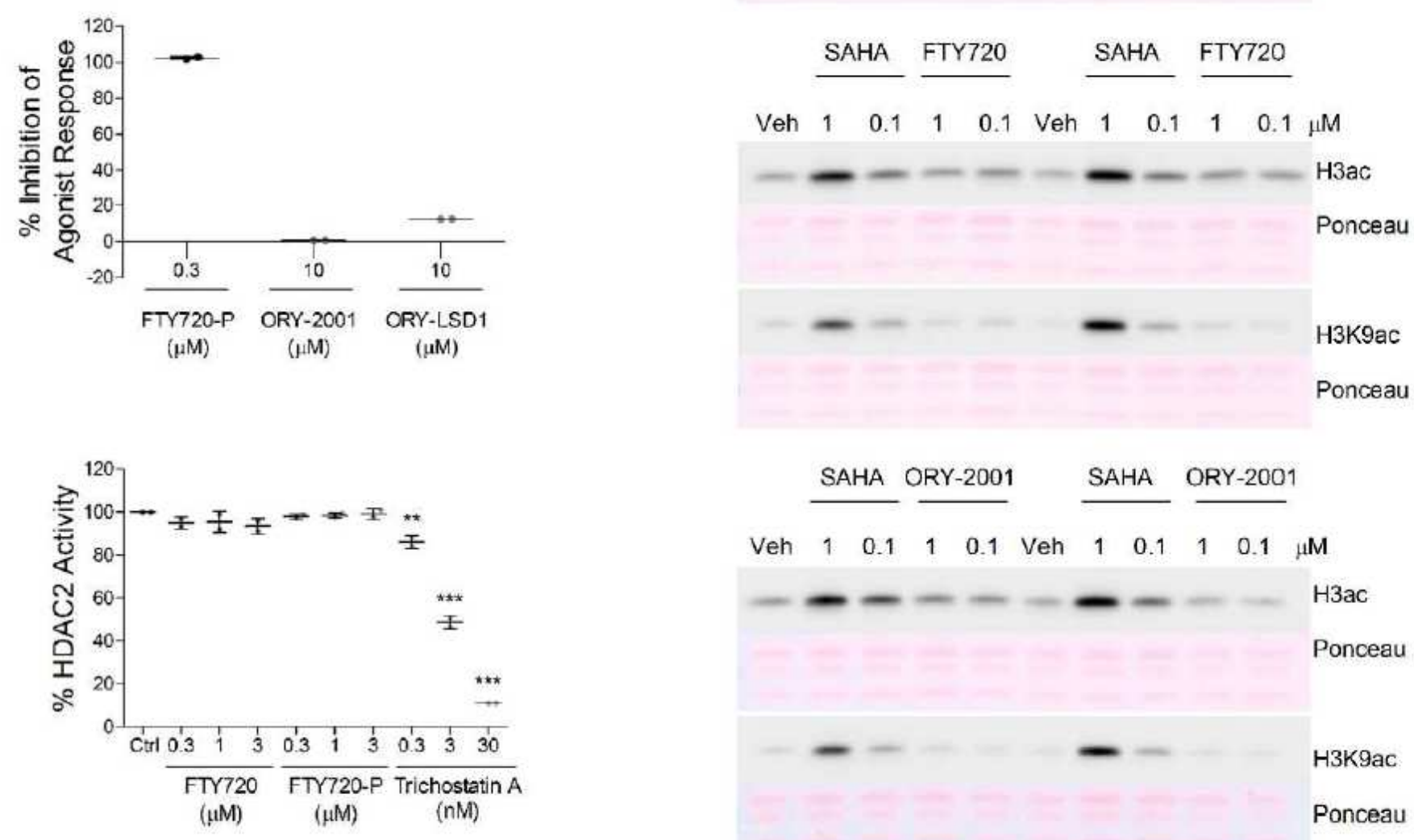

Ponceau 


\section{Figure 7}

Effect of ORY-2001, ORY-LSD1, FTY720 and FTY720-P on S1PR and HDAC. (A) Evaluation of the agonistic effect of the compounds on the human S1P1 receptor. Data are expressed as the percentage of the impedance response of the control agonist (S1P at $0.3 \mu \mathrm{M} ; \mathrm{EC} 50=0.001 \mu \mathrm{M}), \mathrm{n}=2$. (B) Evaluation of the antagonistic effect of the compounds on the human S1P1 receptor. Data are expressed as the percentage of impedance inhibition of the control agonist response ( $\mathrm{S} 1 \mathrm{P}$ at the $\mathrm{EC} 80=0.01 \mu \mathrm{M}), \mathrm{n}=2$. (C) HDAC2 biochemical activity. Data are expressed as percentage of control (no compound) activity, $\mathrm{n}=$ 2. Statistical differences are indicated as ${ }^{* *} p<0.01$; ${ }^{* \star} p<0.001$ using one-way ANOVA test followed by Dunnett's multiple comparison test. (D) Cellular HDAC activity assay. $\mathrm{H} 3$ acetylation (H3ac) levels detected by Western blot analysis using global and H3K9-specific antibodies on cell extracts of SH-SY5Y cells after 2 (left) and $6 \mathrm{hr}$ (right) treatment with SAHA, FTY720-P (top), FTY720 (center) and ORY-2001 (bottom) at 1 and $0.1 \mu \mathrm{M}$. Ponceau $S$ staining was used as loading control. Veh: vehicle. 

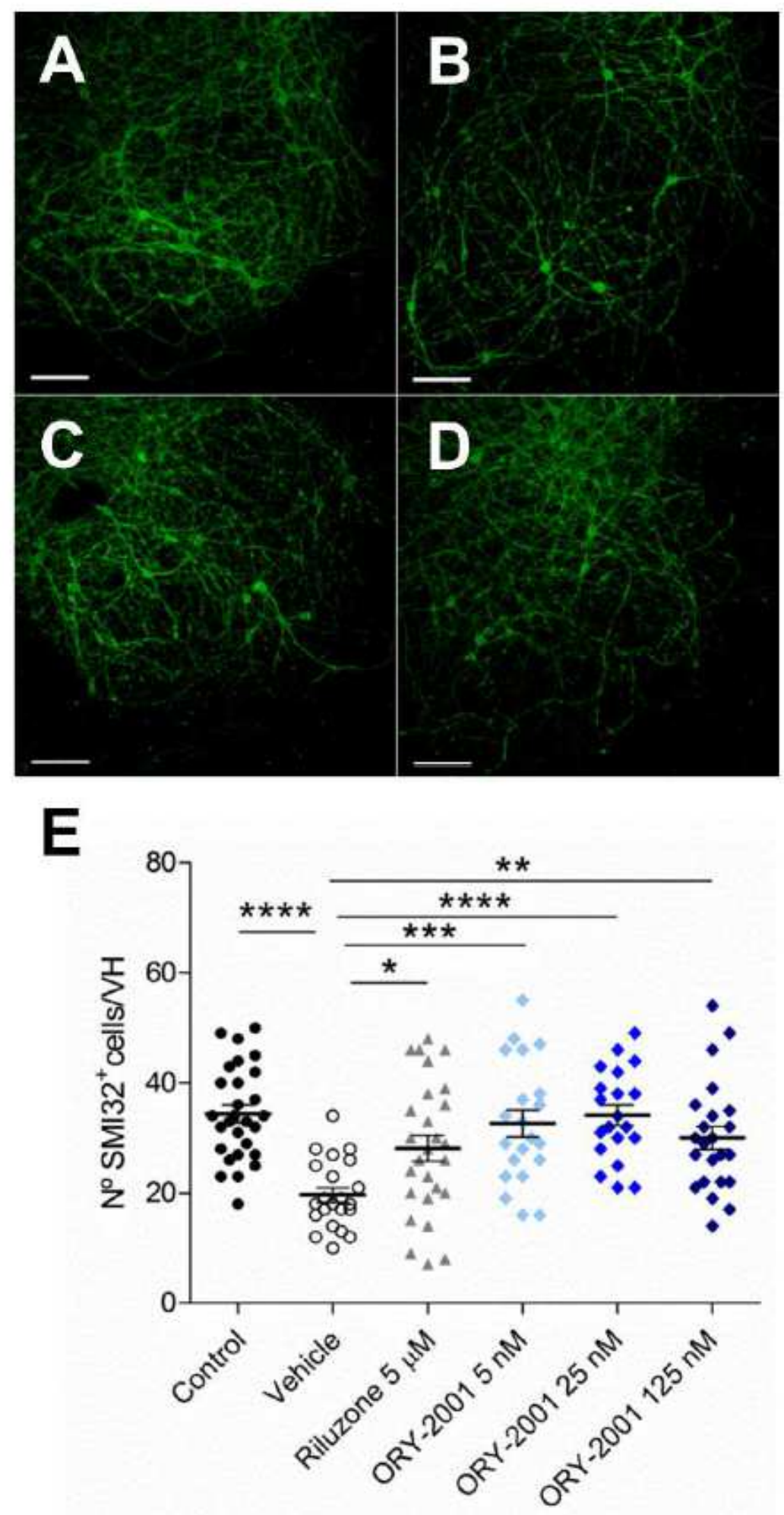

\section{Figure 8}

Effect of ORY-2001 on motoneurons injured by chronic excitotoxicity. (A-D) SMI-32 immunohistochemistry of (A) control spinal cord explants and spinal cord explants exposed to THA treated with (B) vehicle or (C) $5 \mu \mathrm{M}$ riluzole or (D) $5 \mathrm{nM}$ ORY-2001 in a chronic excitotoxicity assay. Scale bar: $100 \mu \mathrm{m}$. (E) Quantification of SMI-32+ motoneurons in control spinal cord explants $(\mathrm{n}=28)$ and explants exposed to THA treated with vehicle $(n=22), 5 \mu$ M riluzone $(n=27)$ or $5(n=21), 25(n=20)$ or 
$125 \mathrm{nM}(\mathrm{n}=23)$ ORY-2001. Data are pooled from 3 experiments performed on different days and presented as mean \pm SEM. Statistical significance was determined by one-way ANOVA followed by Dunnett's post hoc test of all treatments versus vehicle; ${ }^{\star} p<0.05$, ${ }^{\star \star} p<0.01$, ${ }^{\star \star \star} p<0.001$, ${ }^{\star \star \star \star} p<$ 0.0001 .

\section{Supplementary Files}

This is a list of supplementary files associated with this preprint. Click to download.

- Additionalfile1preprint.pdf

- Additionalfile2preprint.pdf

- Additionalfile3preprint.pdf 